\title{
Influence of Irradiance, Flow Rate, Reactor Geometry, and Photopromoter Concentration in Mineralization Kinetics of Methane in Air and in Aqueous Solutions by Photocatalytic Membranes Immobilizing Titanium Dioxide
}

\author{
Ignazio Renato Bellobono, ${ }^{1}$ Mauro Rossi, ${ }^{1}$ Andrea Testino, ${ }^{2}$ Franca Morazzoni, ${ }^{2}$ \\ Riccardo Bianchi, ${ }^{3}$ Giulia de Martini, ${ }^{4}$ Paola Maria Tozzi, ${ }^{4}$ Rodica Stanescu, ${ }^{5}$ Cristina Costache, ${ }^{5}$ \\ Liliana Bobirica, ${ }^{5}$ Mauro Luigi Bonardi, ${ }^{6}$ and Flavia Groppi ${ }^{6}$ \\ ${ }^{1}$ Environmental Research Centre, University of Milan, Camillo Golgi 19 Street, 20133 Milan, Italy \\ ${ }^{2}$ Department of Materials Science, University of Milano Bicocca, Cozzi 43 Street, 20126 Milan, Italy \\ ${ }^{3}$ ISTM, Institute of Molecular Sciences and Technologies, National Research Council (CNR), 20133 Milan, Italy \\ ${ }^{4}$ R\&D Group, BIT srl, 20121 Milan, Italy \\ ${ }^{5}$ Department of Inorganic Technology and Environmental Protection, Polytechnic University of Bucharest, 011061 Bucharest, Romania \\ ${ }^{6}$ LASA, Department of Physics, University of Milan and National Institute of Nuclear Physics (INFN), 20133 Milan, Italy
}

Correspondence should be addressed to Ignazio Renato Bellobono, ignazio.bellobono@unimi.it

Received 19 September 2007; Accepted 13 December 2007

Recommended by M. Sabry Abdel-Mottaleb

Photomineralization of methane in air (10.0-1000 ppm (mass/volume) of C) at 100\% relative humidity (dioxygen as oxygen donor) was systematically studied at $318 \pm 3 \mathrm{~K}$ in an annular laboratory-scale reactor by photocatalytic membranes immobilizing titanium dioxide as a function of substrate concentration, absorbed power per unit length of membrane, reactor geometry, and concentration of a proprietary vanadium alkoxide as photopromoter. Kinetics of both substrate disappearance, to yield intermediates, and total organic carbon (TOC) disappearance, to yield carbon dioxide, were followed. At a fixed value of irradiance $\left(0.30 \mathrm{~W} \cdot \mathrm{cm}^{-1}\right)$, the mineralization experiments in gaseous phase were repeated as a function of flow rate $\left(4-400 \mathrm{~m}^{3} \cdot \mathrm{h}^{-1}\right) . \mathrm{More}-$ over, at a standard flow rate of $300 \mathrm{~m}^{3} \cdot \mathrm{h}^{-1}$, the ratio between the overall reaction volume and the length of the membrane was varied, substantially by varying the volume of reservoir, from and to which circulation of gaseous stream took place. Photomineralization of methane in aqueous solutions was also studied, in the same annular reactor and in the same conditions, but in a concentration range of $0.8-2.0 \mathrm{ppm}$ of $\mathrm{C}$, and by using stoichiometric hydrogen peroxide as an oxygen donor. A kinetic model was employed, from which, by a set of differential equations, four final optimised parameters, $k_{1}$ and $K_{1}, k_{2}$ and $K_{2}$, were calculated, which is able to fit the whole kinetic profile adequately. The influence of irradiance on $k_{1}$ and $k_{2}$, as well as of flow rate on $K_{1}$ and $K_{2}$, is rationalized. The influence of reactor geometry on $k$ values is discussed in view of standardization procedures of photocatalytic experiments. Modeling of quantum yields, as a function of substrate concentration and irradiance, as well as of concentration of photopromoter, was carried out very satisfactorily. Kinetics of hydroxyl radicals reacting between themselves, leading to hydrogen peroxide, other than with substrate or intermediates leading to mineralization, were considered, and it is paralleled by a second competition kinetics involving superoxide radical anion.

Copyright (c) 2008 Ignazio Renato Bellobono et al. This is an open access article distributed under the Creative Commons Attribution License, which permits unrestricted use, distribution, and reproduction in any medium, provided the original work is properly cited.

\section{INTRODUCTION}

Air and water pollution is notoriously a serious problem facing all anthropic activities throughout the world. To reduce this problem, many physical, chemical, and biological technologies are available [1]. Conventional methods based on stripping, such as adsorption by activated carbon, result only in transfer of pollutants from one phase to another, and not to integral destruction. On another side, thermal oxidation techniques may be valuable but surely not cost effective, particularly at low contamination values, due to the added fuel consumption; furthermore these methods contribute to 
massive carbon dioxide production. Photocatalytic processes on semiconductors, on the contrary, are one of the newer advanced oxidation processes (AOP) techniques. They were developed during the last twenty five years [1-9], in the presence of catalysts, such as titanium dioxide, with UV radiation. If the UV radiation is from the sun, the treatment costs are reduced drastically by transforming photocatalysis in one of the most appealing and environmentally friendly processes for complete mineralization of organic pollutants. Furthermore, photocatalytic processes may be used as a pretreatment of toxic chemicals, in order to convert them into fully biodegradable compounds to be finally processed by the most economical technology presently available, that of active sludge [10]. Combination of photocatalysis with active sludge techniques is undoubtedly one of the most promising technologies to degrade and mineralize, efficiently and inexpensively, wastes containing toxic compounds.

The major problem in photocatalysis, from the point of view of industrial applicability, is given by the necessity of immobilizing the semiconductor photocatalyst, by firmly anchoring it to a suitably reacting structure, and of reaching the highest performance as possible in photocatalytic reactors, in continuous mode [11]. These two aspects (kind of immobilization, as linked to kinetic modeling of the whole course of the photomineralization process, and quantum yields) need therefore to be considered as priority options for engineering applications. In all preceding papers of this series (see, e.g., among the most recent ones [12-14]), the main concern has been devoted to these topics, and immobilization of semiconductor photocatalyst and its photopromoting agents in a membrane structure has been the choice, in order to manufacture modular membrane reactors, the performance of which has been effectively estimated as one of the highest for energy efficiency [11].

From the point of view of mechanisms of surface photochemical reactions that take place in heterogeneous systems, a recent article [15] has criticized the a priori assumed validity of the Langmuir-Hinshelwood kinetic model to interpret the experimental observations, as well as the assertion that the kinetics of a heterogeneous photoreaction are either first-order or half-order dependent on photon flow. Such a criticism has already been emphasized in the literature also from the point of view of engineering applications, and dates back to earlier pilot plant studies [16], which have shown, for example, the influence of flow rate on apparent thermodynamic constant of adsorption/desorption, relative to the Langmuir-Hinshelwood model, as well as the inadequacy of this model to fit kinetics of mineralization, other than in the segment of the initial rate [12-14], particularly when using immobilized photocatalysts, so that this pseudothermodynamic parameter of the Langmuir-Hinshelwood model should have a, partly at least, kinetic character.

It is well known that, in carefully deaerated water, and in the absence of any kind of oxygen donors, following radiation absorption by the semiconductor, photogenerated holes react with hydroxyl groups of water to give hydroxyl radicals - $\mathrm{OH}$, while photogenerated electrons reduce hydroxonium ions and cause hydrogen evolution. On the contrary, in aerated water, the photogenerated conduction-band electrons reduce dissolved oxygen or other oxygen donors added to this purpose to yield $\mathrm{O}_{2}^{--}$in acid-base equilibrium with $\mathrm{HO}_{2}^{\bullet}$. The possibility of the latter reaction to take place quantitatively is of uttermost importance in environmental applications of photocatalyis, because, in the last case, oxidation of organic compounds may be carried out by $\mathrm{HO}_{2}^{\bullet}$ together with ${ }^{\bullet} \mathrm{OH}$ radicals. This allows to obtain a fourfold maximum quantum yield with respect to that permissible if each absorbed photon would be able to produce a single hydroxyl radical only. This occurrence has been shown as effective [12, 16, 17] when using, for example, ozone as oxygen donor and when promoting the activity of the immobilized semiconductor by suitable doping agents, such as $\mathrm{Co}$ (III) or V(V), coimmobilized with the semiconductor itself in a membrane structure and acting as scavengers of generated photoelectrons.

Comparison of efficiency of different kinds of supported or immobilized photocalysts, and objective, quantitative characterization of their photocatalytic power are thus the major problems to define kinetic reactivity. In most of literature works, this kind of assessment is often made simply by matching qualitatively concentration profiles of degraded species. In addition, in many cases described in the literature, no regard is made to total organic carbon (TOC) mineralization, but merely to the transformation of substrate into some intermediate compound, as the first step of the complicated reaction mechanism leading finally to carbon dioxide. Moreover, it is a common practice, even when quantitative evaluations are made, to consider the photocatalytic process as a first-order reaction, while it has been definitely ascertained that apparent reaction order varies with the concentration of substrate $[13,16]$. With an evident transition from a limiting zero-order, at high concentrations, to a limiting first-order at low concentrations. Modeling of photocatalytic reactions, on the contrary, in a wide range of concentrations, and over all the kinetic concentration profile of TOC, leading to full mineralization, has been approached systematically in previous papers of this series $[12-14,18]$, mostly for processes carried out in aqueous solutions. This has been done also from the standpoint of quantum yields and energy efficiencies, a very important aspect, which is often neglected in the literature pertinent to photocatalysis.

In the present paper, modeling will be extended to photocatalytic kinetic runs in gaseous phase, by using methane in air as a model molecule, both to apply the four-parameter kinetic model used successfully in preceding studies [1214,18 ] for fitting the whole kinetic profile, and to broaden the application of this model, as a function of all variables which show an influence on the photocatalytic kinetics, and consequently play a primary role in all trustworthy characterization procedures of immobilized materials. The dependence of the four parameters of the kinetic model cited above $[12-14,18]$ on flow rate, on reactor geometry, on radiation flow, and on the concentration of a proprietary photopromoter coimmobilized with the semiconductor in the photocatalytic membranes will be first examined. By this way, information, preliminarly investigated in a previous work [19] on methane in air, will be implemented and get deeper. Secondly, the influence of these variables on the same parameters above [12-14], relatively to experiments carried 
out in aqueous solutions, will be checked in order to systematically compare reactivity in liquid and gaseous phases. Finally, the dependence of quantum yields on the concentration of substrate and on photon flow will be considered and analyzed, with the goal of attaining, by all these variables expressed in the most convenient ways, a complete rationalization of the photocatalytic process, both in liquid and gaseous phases, from the engineering point of view, as well from the perspective of establishing a reliable standardization method of the photocatalytic performance of materials.

\section{EXPERIMENTAL}

\subsection{Materials}

Methane was obtained from Fluka (GC purity greater than $99.8 \%$ ). It was used as received with no further purification. Ultra pure water, to be used for preparation of methane solutions, or to be aerosolized in the reactor, when performing kinetic runs of methane in air, to maintain a $100 \%$ relative humidity at the operating temperature of the photoreactor (maximum contents of $\mathrm{Na}^{+}$and heavy metal ions 0.02 and $0.004 \mathrm{mg} \mathrm{Kg}^{-1}$, resp.), was obtained by cross-flow ultrafiltration on composite membranes immobilizing active carbon and nuclear grade ion exchange resins, as described [20]. Concentration of substrate in the gas phase was 10.0-1000 ppm (mass expressed as carbon/volume), while in aqueous solution it could be varied, for solubility reasons, only between 0.80 and $2.00 \mathrm{ppm}$.

\subsection{Photocatalytic membranes}

The photocatalytic membranes (PHOTOPERM BIT/313), kindly supplied by B.I.T. srl, Milan, I, were standard photocatalytic membranes, immobilizing $30 \pm 3 \mathrm{wt}$.\% of titanium dioxide (P25 by Degussa, Germany) in the absence and in the presence of a photocatalytic promoter, as cocatalyst. In the latter case, a proprietary synergic mixture of tri-( $t$-butyl)- and tri-(i-propyl)vanadate(V) [10] was used, by varying the vanadium concentration in the range $0.1-$ $10 \mathrm{~mol} / \mathrm{mol} \%$ with respect to that of titanium. Photocatalytic membranes $[16,21]$, and more generally membranes, prepared by photografting, to immobilize reagents, catalysts, and sorbents [22-24], were described and characterized in previous studies. These membranes were prepared (patents pending) by grafting and graft-polymerizing, onto a nonwoven microporous polypropylene tissue, $250 \pm 9 \mathrm{~g} \cdot \mathrm{m}^{-2}$ of a prepolymeric blend containing $30 \pm 3 \mathrm{wt} . \%$ of titanium dioxide (P25 by Degussa, Germany), under rheological control, in the presence of proprietary photoinitiating and photosensitising systems.

\subsection{Apparatus and procedures}

The laboratory-scale photoreactor was substantially the same as that already described [25], with some differences in the materials and operating procedures, as it will be specified later on, and the change is that it was made gas tight to avoid any leakage of substrate and/or intermediates through the vapour phase, both when operating with gaseous methane in air or with its aqueous solutions. Contrarily to procedure of previous work [19], in which, when operating in the gaseous phase, an aqueous solution of hydrogen peroxide was aerosolized continuously into the reactor, in order to supply the stoichiometric amount of this oxygen donor, in the present work, only ultra pure water was aerosolized in the photoreactor, just to maintain a $100 \%$ relative humidity at $318 \pm 3 \mathrm{~K}$, which was the operating temperature of the reactor. This was made, to check the influence on the rate of the oxygen content of air, instead of using hydrogen peroxide. Stoichiometric hydrogen peroxide, on the contrary, was always used when operating with aqueous solutions of methane. Overall volume of gaseous or liquid phase being treated was $4.000 \pm 0.005 \mathrm{~L}$, in standard experiments; the ratio between the overall reacting volume and the length of the lamp, corresponding to the length of the irradiated side of the membrane, was $160 \pm 6 \mathrm{~cm}^{3} / \mathrm{cm}$. A high-pressure mercury arc lamp with a nominal power of $1.00 \mathrm{KW}$ was employed, kindly supplied by Chimia Prodotti e Processi (Muggiò, Milan, Italy): it was further provided with a step-by-step power regulation device, so that power absorbed by the membrane, as determined actinometrically, could be varied between 0.10 and $4.0 \mathrm{~W} \cdot \mathrm{cm}^{-1}$. The membrane being concentric to the lamp in the photoreactor used, absorbed power per unit length of lamp was also the same, if referred to unit length of membrane. At $0.30 \mathrm{~W} \cdot \mathrm{cm}^{-1}$, the overall power absorbed by the membrane, within the absorption range of immobilized semiconductor, in the experimental conditions of the present work, was $30 \mathrm{~W}$, corresponding to $4.45 \times 10^{-5}$ Einstein $\mathrm{s}^{-1}$. In this paper, as well as in all preceding papers of this series, when concerning laboratoryscale experiments carried out in the presence of hydrogen peroxide as an oxygen donor, the radiating flow, unless otherwise stated, being filtered by a suitable borosilicate glass, corresponded to a radiation wavelength range from the band gap of $\mathrm{TiO}_{2}$ downwards to $315 \mathrm{~nm}$, so that direct photolysis of hydrogen peroxide to give hydroxyl radicals was inhibited. Owing to the refrigeration system of the lamp, by means of water circulating in the lamp sheath, made of quartz, mean temperature, during the runs, was $318 \pm 3 \mathrm{~K}$.

In the present, as well as in previous papers of this series, membranes were placed and fixed coaxially with the lamp, in such a way that the flow was perpendicular to the membrane. Owing to the microporous structure of the membrane, the pressure drop was very modest: it corresponded to 0.9-1.6 $\mathrm{mm} \mathrm{Hg}$, when the flow rate of the liquid system was $4 \mathrm{~m}^{3} / \mathrm{h}$ in the laboratory-scale photoreactor.

During some of the gaseous phase experiments, the flow rate was varied between 4 and $400 \mathrm{~m}^{3} / \mathrm{h}$. In these experiments, in order to examine the influence of flow rate on parameters of kinetic model used, irradiance was fixed at a value corresponding to $0.30 \mathrm{~W} \cdot \mathrm{cm}^{-1}$.

The standard flow rate in gaseous phase kinetic runs, to study the influence of irradiance on parameters above, was $300 \mathrm{~m}^{3} / \mathrm{h}$. In this latter experimental condition of flow rate, the ratio between the overall reaction volume and the length of the membrane was varied substantially by varying the volume of reservoir, from and to which circulation of 
gaseous stream took place. This was carried out to study the influence of reactor geometry on kinetic parameters above, and by operating at a constant irradiance, corresponding to $0.30 \mathrm{~W} \cdot \mathrm{cm}^{-1}$

The disappearance of methane, as such, was followed by GC-MS quantitative analysis into the injection port of a GC-MS system. A Varian 3400 with a septum-equipped programmable injector was used. In the GC oven, a $30 \mathrm{~m} \times$ $0.53 \mathrm{~nm}$ DB5MS megabore column was installed with the following temperature programme: $20^{\circ} \mathrm{C}$ for 1 minute followed by a temperature raise of $5^{\circ} \mathrm{C} / \mathrm{min}$ to $240^{\circ} \mathrm{C}$, which was held for 4 minutes.

As a carrier gas, He was used at a flow rate of $25 \mathrm{~mL} / \mathrm{min}$. The GC was interfaced via jet separator $(0.3 \mathrm{~mm} \mathrm{Hg}$ in the separator and $0.03 \mathrm{~mm} \mathrm{Hg}$ in the analyser) and a transfer line $\left(270^{\circ} \mathrm{C}\right)$ to an ITS40 ion trap mass-spectrometer (ITMS). The ion trap was operated at $300^{\circ} \mathrm{C}$ in the electron impact mode, scanning from $35 \mathrm{M} / \mathrm{Z}$ to $550 \mathrm{M} / \mathrm{Z}$ in 1.5 second. The GC-ITMS data were acquired on a 386/387 Compaq personal computer with Saturn I software (Varian). Methane was identified by its mass spectrum and standard samples. Quantification was based on seven-point calibration curves using, as internal standard, a standard sample containing perdeuterated methane.

In order to study the relationship between the rate of methane disappearance, as such, and the overall rate of organic carbon disappearance, this latter was also followed by total organic carbon (TOC) analysis. To this purpose, a Shimadzu TOC-V instrument was used, by which the contribution of inorganic carbon present was always evaluated, in order to obtain TOC by difference from total carbon and inorganic carbon determinations. Determinations were accurate within 20 ppb C.

During all the duration of the runs, no sensible decrease of activity of the immobilized photocatalyst was observed, as checked both by random repetition of experiments at various initial concentrations of the hydrocarbons, both in the liquid and in the gaseous phase, and by reiteration of whole series of tests at the beginning and at the end of the prolonged period, throughout which experimentation has been carried out.

\subsection{Kinetic modeling}

Kinetic modeling was carried out by generalizing procedures followed in preceding papers $[12,13,26]$. These procedures have not the goal of proposing and checking photochemical mechanisms, but simply its goal is to reproduce closely experimental data, for engineering purposes, without any strict implication on the true mechanisms.

If mineralization of substrate $\mathrm{S}$ to $\mathrm{CO}_{2}$ is supposed to occur through one single intermediate I, following scheme (1)

$$
\mathbf{S} \longrightarrow \mathbf{I} \longrightarrow \mathrm{CO}_{2}
$$

and if both $\mathbf{S}$ and $\mathbf{I}$ show a competitive apparent adsorption onto the immobilized semiconductor surface, as expressed by apparent adsorption constants $K_{1}$ and $K_{2}$, respectively, models for experimental data, used in nonlinear regression anal- ysis, are not expressed in a closed-form equation

$$
y_{(\text {calc })}=f(x)
$$

but as the following system of first-order ordinary differential equations in the dependent variables $C_{\mathrm{S}}, C_{\mathrm{I}}$, and $C_{\mathrm{CO}_{2}}$ :

$$
\begin{aligned}
\left(\frac{d C_{\mathrm{S}}}{d t}\right) & =\frac{-k_{1} \cdot K_{1} \cdot C_{\mathrm{S}}}{1+K_{1} \cdot C_{\mathrm{S}}+K_{2} \cdot C_{\mathrm{I}}}, \\
\left(\frac{d C_{\mathrm{I}}}{d t}\right) & =\frac{k_{1} \cdot K_{1} \cdot C_{\mathrm{S}} \cdot k_{2} \cdot K_{2} \cdot C_{\mathrm{I}}}{1+K_{1} \cdot C_{\mathrm{S}}+K_{2} \cdot C_{\mathrm{I}}}, \\
\left(\frac{d C_{\mathrm{CO}_{2}}}{d t}\right) & =\frac{k_{1} \cdot K_{1} \cdot C_{\mathrm{I}}}{1+K_{1} \cdot C_{\mathrm{S}}+K_{2} \cdot C_{\mathrm{I}}},
\end{aligned}
$$

where $C$ denotes concentrations of species to which the pertinent suffix refer, $t$ time; $k_{1}$ and $k_{2}$ the kinetic constants relative to degradation of $\mathbf{S}$ and $\mathbf{I}$, respectively. Intermediate $\mathbf{I}$ is supposed to simulate the behavior of all the often uncountable, numerous intermediates, which are on the route from the substrate $\mathbf{S}$ to $\mathrm{CO}_{2}$. Experimentally speaking, only kinetic profiles of $\mathbf{S}$ and $\mathrm{CO}_{2}$ may be easily followed. Even if, for the molecule chosen in the present investigation, a limited number of intermediates may be reasonably envisaged from the substrate to $\mathrm{CO}_{2}$, the same is not true $[12,13,26]$ for aromatic and/or heterocyclic compounds, or still for long-chain aliphatics, which have been the object of previous investigations.

Random errors in $t$ can be neglected, and only the random errors in the dependent variables are considered.

The error sum, $G\left(k_{1}, k_{2}, K_{1}, K_{2}\right)=\sum_{i=1}^{n} w_{i}\left[C_{\mathbf{S}(\exp )}^{i}-\right.$ $\left.C_{\mathbf{S}(\text { calc })}^{i}\right]^{2}$, is minimized to obtain the best values of the $k_{1}, k_{2}, K_{1}, K_{2}$ parameters; $C_{\mathbf{S}(\exp )}^{i}$ and $C_{\mathbf{S}(\text { calc })}^{i}$ represent the $n$ measured and calculated substrate concentration values, respectively, and $w_{i}=1 / \sigma^{2}\left(C_{\mathbf{S}(\exp )}^{i}\right)$ is the weighting factor.

Furthermore the conservative balance of carbon has to be accounted for and verified experimentally, all concentrations of substrate and intermediate being expressed in terms of carbon content, as obtained from TOC analysis

$$
\begin{aligned}
C_{\mathrm{c}} & (\text { at time } t) \\
& =C_{\mathrm{TOC}}(\text { at time } 0) \\
& =C_{\mathrm{S}}(\text { at time } t)+C_{\mathrm{I}}(\text { at time } t)+C_{\mathrm{CO}_{2}}(\text { at time } t)
\end{aligned}
$$

where $C_{\mathrm{c}}$ represents the total carbon, both organic and inorganic, carbon dioxide representing the final product of the mineralization process

$C_{\text {Toc }}$ (at time 0$)$ being equal to $C_{S}$ (at time 0$)$,

$C_{\text {TOC }}\left(\right.$ at time $t$ ) being equal to $C_{\mathrm{S}}($ at time $t)+C_{\mathrm{I}}($ at time $t)$.

The major limitation of (6) is to regard only intermediates containing carbon, which is, anyway, the most common 
condition in degradation of organics. If this should not be the case, (6) should be substituted by

$$
\begin{aligned}
& C_{\mathrm{c}}(\text { at time } t) \\
& \quad=C_{\text {TOC }}(\text { at time } t)=C_{\mathrm{S}}(\text { at time } t)=C_{\mathrm{CO}_{2}}(\text { at time } t)
\end{aligned}
$$

and substitute (5) by

$$
\left(\frac{d C_{\mathrm{CO}_{2}}}{d t}\right)=-\left(\frac{d C_{\mathrm{S}}}{d t}\right)
$$

Equations (3)-(6) constitute a suitable model for temporal disappearance of TOC, which is a relevant analytical parameter to follow environmental pollution problems.

When $t=0$ (beginning of photodegradation), $C_{\mathrm{I}}$ is completely negligible with respect to $C_{S}$. Furthermore, the hypotheses that $k_{1} \sim k_{2}$ and symmetrically that $K_{1} \sim K_{2}$, even if this is not always true, may be used, in some cases, simply as a starting approximation. With this approximation, (3) can be simplified to

$$
r_{0}=\frac{k_{1} \cdot K_{1} \cdot C_{0}}{1+K_{1} \cdot C_{0}},
$$

where $r_{0}$ is the initial rate, and $C_{0}$ represents the initial concentration of substrate $\mathbf{S}$. The reciprocal of (9) has exactly the same form of the Langmuir-Hinshelwood model (13). Moreover, being initially $C_{\mathrm{I}}=0$, from (5) and (6) one obtains, at $t=0$,

$$
\left(\frac{d C_{\mathrm{CO}_{2}}}{d t}\right)=\left(\frac{d C_{\mathrm{TOC}}}{d t}\right)=0
$$

In other words, the formation of carbon-containing intermediates, if the latter are not photodegraded yielding $\mathrm{CO}_{2}$ at a higher rate than that of the substrate, gives rise to a characteristic plateau in the curve of TOC content versus time. This trend is only approximated experimentally, both because there is often a preferential, even if not prevailing, route to rapid $\mathrm{CO}_{2}$ formation from $\mathrm{S}$, and because intermediates are often more reactive than the substrate itself towards photodegradation, so that TOC disappearance is initially low, particularly in aromatic compounds, usually around one order of magnitude lower than that of the substrates, but is still measurable.

Now, let us suppose that a time $t^{*}$ exists, such as that for $t>t^{*}, C_{\mathrm{S}} \ll C_{\mathrm{I}}$. At time $t^{*},(4)$ becomes

$$
\frac{d C_{\mathrm{I}}}{d t} \sim-\frac{k_{2} \cdot K_{2} \cdot C_{\mathrm{I}}}{1+K_{2} \cdot C_{\mathrm{I}}},
$$

and as for $(6)$ in these conditions $C_{\mathrm{TOC}} \sim C_{\mathrm{I}}$, (11) becomes

$$
\frac{d C_{\mathrm{TOC}}}{d t} \sim-\frac{k_{2} \cdot K_{2} \cdot C_{\mathrm{TOC}}}{1+K_{2} \cdot C_{\mathrm{TOC}}} .
$$

An important experimental result is thus substantiated and rationalized in these cases, where the rate of mineralization of intermediates is much lower than that of transformation of substrate into an intermediate (the cases of aromatic compounds particularly): the curve $C_{\mathrm{TOC}}$ versus time explicitly follows a Langmuirian-type rate law (13), by which $k$ and $K$ parameters acquire the physical significance of $k_{2}$ and $K_{2}$, as stated above.

That time $t^{*}$ effectively exists, as a time at which the substrate is completely converted into intermediates, even with a modest decrease of TOC content and nearly complete mineralization of eventual heteroatoms present in the substrate, is experimentally recognized by both literature data [27] and by results of our preceding work [26].

In most cases, both $k$ and $K$ couples are accessible experimentally, as starting values from initial-rate data, relative to substrate, and TOC as well, using the Langmuirian equation (13)

$$
\frac{1}{r_{0}}=\frac{1}{k}+\frac{1}{k K C_{0}}
$$

where $r_{0}$ is the initial rate of substrate disappearance, whether measured by direct analysis of substrate itself (to obtain the $k_{1}$ and $K_{1}$ couple) or by the rate of decrease of total organic carbon (TOC) as a function of time (to obtain the $k_{2}$ and $K_{2}$ couple). The values drawn from (13) may be used as starting values to find the absolute minimum in the error sum, $G$, with respect to $k_{1}, K_{1}, k_{2}$ and $K_{2}$ kinetic parameters. In particular cases, as stated before, when only $k_{2}$ and $K_{2}$ values are available experimentally by TOC measurements, the approximation $k_{1} \sim k_{2}$ and $K_{1} \sim K_{2}$ can be used as a starting point in the minimization algorithm as has been suggested on a theoretical basis [28]. Variation of kinetic parameters, in order to optimize the fitting, may additionally be restricted within the expected range of experimental uncertainty, but also chemical considerations may be of great help, as well as simultaneous consideration of $k$ and $K$ parameters for other chemically related substrates and/or intermediates, which may be studied by the same methodology.

\subsection{Modeling of quantum yields as a function of irradiance and of substrate concentration}

By using the optimized parameters of the section above, the rates of photomineralization were evaluated as a function of initial concentration, $C_{0}$, and consequently, by operating at a certain value of the photon flow, the corresponding quantum yields $\Phi_{0}$ were obtained.

Quantum yields $\Phi_{0}$, calculated from rates, followed an apparently Langmuirian function of initial concentration of substrate $C_{0}$, by which $\Phi_{\infty}$ values at infinite concentration could be obtained as

$$
\frac{1}{\Phi_{0}}=\frac{1}{\Phi_{\infty}}+\frac{1}{\Phi_{\infty} C_{0} K}
$$

where the $K$ value substantially coincided with the lowest between the two $K_{1}$ and $K_{2}$ constants above, for many molecules being $K_{1} \sim K_{2}$.

Finally, by repeating all sets of experiments, at different values of the absorbed radiant power per unit length of photocatalytic membrane, which was varied in the range $0.10-$ $4.0 \mathrm{~W} \cdot \mathrm{cm}^{-1}$, and by applying (14) to each set of these experiments, the $\Phi_{\infty}$ values, as a function of the absorbed radiant power, per unit length of photocatalytic membrane, were obtained. 
TABLe 1: Parameters*, $k_{1}$ and $K_{1}, k_{2}$ and $K_{2}$, able to fit the whole photomineralization curve, following Scheme (2), at various values of absorbed power per unit length of membrane expressed in $\mathrm{W} \cdot \mathrm{cm}^{-1}$. They were obtained by the optimization of kinetic curves, by using the set of differential equations corresponding to kinetic model of Scheme (2). All the parameters are expressed in ppm of carbon (mass of $\mathrm{C} /$ volume, $\mathrm{mg} / \mathrm{L}$ ) and refer to the photodegradation of methane in gaseous phase, and in aqueous solutions, in the presence of stoichiometric hydrogen peroxide (for the aqueous solutions) or of dioxygen of air (for the gas-phase experiments), as oxygen donors (treated volume of the gas phase or of the aqueous solutions $4.00 \mathrm{~L}$; membrane length $100.0 \pm 0.5 \mathrm{~cm}$; ratio between overall reaction volume and membrane length $160 \pm 6 \mathrm{~cm}^{3} / \mathrm{cm}^{2} ;$ PHOTOPERM ${ }^{\circledR}$ BIT/313 membranes immobilizing $30 \pm 3 \mathrm{wt} \% \mathrm{TiO}_{2}$, in the absence of any photopromoter).

\begin{tabular}{|c|c|c|c|c|}
\hline \multicolumn{5}{|c|}{ Aqueous solutions } \\
\hline Absorbed power per unit length of membrane $\left(\mathrm{W} \cdot \mathrm{cm}^{-1}\right)$ & $k_{1}(\mathrm{ppm} \mathrm{C} / \mathrm{min})$ & $k_{2}(\mathrm{ppm} \mathrm{C} / \mathrm{min})$ & $K_{1}(\mathrm{ppm} \mathrm{C})^{-1}$ & $K_{2}(\mathrm{ppm} \mathrm{C})^{-1}$ \\
\hline 0.15 & $0.111(3)$ & $0.293(3)$ & $0.0124(3)$ & $0.0086(3)$ \\
\hline $0.30^{* *}$ & $0.224(1)$ & $0.584(2)$ & $0.0126(3)$ & $0.0089(3)$ \\
\hline 0.70 & $0.494(2)$ & $1,23(4)$ & $0.0130(3)$ & $0.0091(3)$ \\
\hline 0.90 & $0.589(3)$ & $1.45(4)$ & $0.0131(4)$ & $0.0090(3)$ \\
\hline 1.50 & $0.802(4)$ & $1.95(4)$ & $0.0125(3)$ & $0.0086(4)$ \\
\hline 2.00 & $0.890(3)$ & $2.24(3)$ & $0.0133(6)$ & $0.0090(2)$ \\
\hline 3.00 & $0.896(4)$ & $2.39(6)$ & $0.0128(3)$ & $0.0088(2)$ \\
\hline 4.00 & $0.894(5)$ & $2.28(7)$ & $0.0127(2)$ & $0.0086(3)$ \\
\hline \multicolumn{5}{|c|}{ Gas phase } \\
\hline Absorbed power per unit membrane length $\left(\mathrm{W} \cdot \mathrm{cm}^{-1}\right)$ & $k_{1}(\mathrm{ppm} \mathrm{C} / \mathrm{min})$ & $k_{2}(\mathrm{ppm} \mathrm{C} / \mathrm{min})$ & $K_{1}(\mathrm{ppm} \mathrm{C})^{-1}$ & $K_{2}(\mathrm{ppm} \mathrm{C})^{-1}$ \\
\hline 0.15 & $0.115(6)$ & $0.288(7)$ & $0.0127(7)$ & $0.0085(7)$ \\
\hline 0.30 & $0.223(5)$ & $0.581(5)$ & $0.0131(9)$ & $0.0082(6)$ \\
\hline 0.90 & $0.586(3)$ & $1.57(4)$ & $0.0131(4)$ & $0.0091(3)$ \\
\hline 1.50 & $0.805(4)$ & $1.92(4)$ & $0.0125(3)$ & $0.0087(2)$ \\
\hline 2.00 & $0.891(3)$ & $2.33(3)$ & $0.0130(3)$ & $0.0090(2)$ \\
\hline 3.00 & $0.892(4)$ & $2.37(5)$ & $0.0127(3)$ & $0.0088(2)$ \\
\hline 4.00 & $0.889(5)$ & $2.32(6)$ & $0.0129(4)$ & $0.0091(2)$ \\
\hline
\end{tabular}

* Uncertainties are indicated between parentheses and expressed, relatively to the last digits, as probable errors of the means of optimized values from 9 sets of runs in the range of concentrations tested.

** Data relative to these experiments were taken from [14].

\subsection{Modeling of quantum yields as a function of photopromoter concentration}

For experiments in which the photopromoter was added, the same procedure described in the preceding paragraph was adopted, and the $\Phi_{\infty}$ values obtained at a high value of absorbed irradiance, typically $\Phi_{\infty}$ values at $4 \mathrm{~W} \cdot \mathrm{cm}^{-1}$, much smaller than the maximum allowable $\Phi_{\infty}$ values corresponding to irradiances tending to zero, were plotted as a function of concentration of photopromoter in the photocatalytic membrane.

\section{RESULTS AND DISCUSSION}

Photomineralization of methane in air at $100 \%$ relative humidity, and in a concentration range corresponding to 10.0-1000 ppm (mass/volume) of carbon, was studied at $318 \pm 3 \mathrm{~K}$, in a laboratory-scale reactor, by using dioxygen of air as an oxygen donor, and by photocatalytic membranes immobilizing $30 \pm 3 \%$ of titanium dioxide, as a function of absorbed power per unit length of membrane, expressed in $\mathrm{W} \cdot \mathrm{cm}^{-1}$. The latter was varied in the range $0.15-$ $4.0 \mathrm{~W} \cdot \mathrm{cm}^{-1}$. This is a convenient measure of power absorbed per unit apparent geometrical membrane surface, since, owing to the annular geometry of photoreactor, absorbed power per unit length, divided by membrane circumference, yields exactly that value. Kinetics of both substrate disappearance, to yield intermediates, and total organic carbon (TOC) disappearance, to yield carbon dioxide, were followed.

At a fixed value of irradiance, corresponding to $0.30 \mathrm{~W} \cdot \mathrm{cm}^{-1}$, the mineralization experiments in gaseous phase were repeated as a function of flow rate, which was varied between 4 and $400 \mathrm{~m}^{3} \cdot \mathrm{h}^{-1}$. Moreover, at a standard flow rate of $300 \mathrm{~m}^{3} \cdot \mathrm{h}^{-1}$, the ratio between the overall reaction volume and the length of the membrane was varied, substantially by varying the volume of reservoir, from and to which circulation of gaseous stream took place.

Photomineralization of methane in aqueous solutions was also studied, in the same reactor and in the same conditions, but in a concentration range of $0.8-2.0$ ppm of carbon, and by using stoichiometric hydrogen peroxide as an oxygen donor.

\subsection{Parameters of kinetic model as a function of absorbed power per unit length of membrane}

Treating of experimental data by the kinetic model above (see Experimental) allowed to obtain, for all sets of kinetic runs, performed as a function of concentration, two couples of parameters, $k_{1}$ and $K_{1}, k_{2}$ and $K_{2}$, which fitted the whole photomineralization curve, and not only its initial segment, as the Langmuirian parameters generally do. These parameters, as a function of absorbed power per unit membrane length, are reported in Table 1, both for experiments carried 


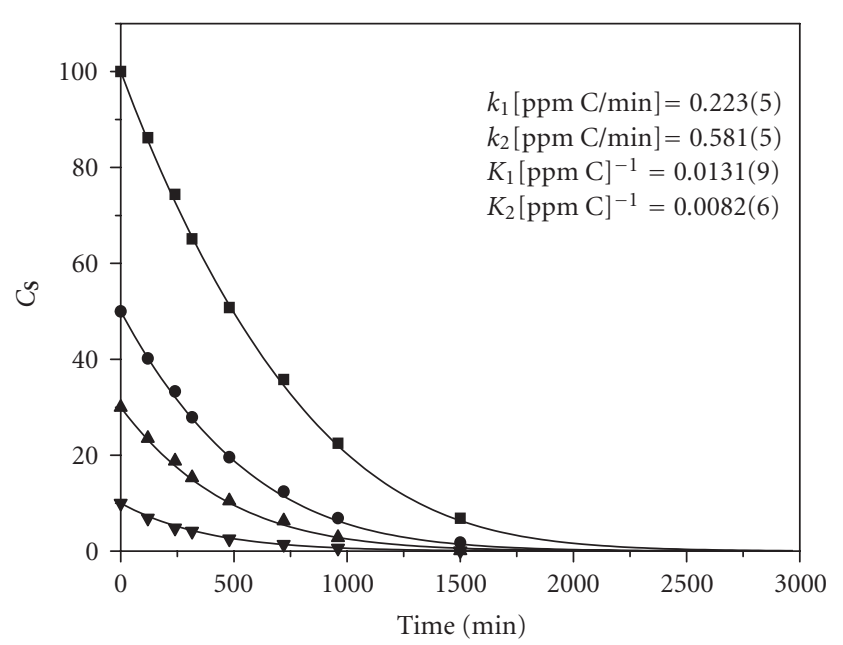

FIgURE 1: Kinetics of disappearance of methane, as substrate, from the gas phase, with $0.30 \mathrm{~W} \cdot \mathrm{cm}^{-1}$ of absorbed radiation power per unit membrane length. Concentrations, $C_{\mathrm{S}}$ in $\mathrm{mg} / \mathrm{L}$, for methane, are expressed as carbon, which was not transformed into intermediates, as a function of time, expressed in minutes, as time necessary to treat $1 \mathrm{~L}$ of gas phase. Photocatalytic membranes used in these experiments did not contain any photopromoting agent.

out on methane in aqueous solutions, with hydrogen peroxide as an oxygen donor, as well as in the gaseous phase, with dioxygen of air as oxygen donor. In this same Table, the values measured in aqueous solutions, at $0.30 \mathrm{~W} \cdot \mathrm{cm}^{-1}$, in a preceding work [14], are also reported. The very satisfactory fitting of experimental kinetic data by this model, notwithstanding its extreme simplicity, is shown, as an example, in Figures 1 and 2 for the kinetic curves of disappearance of methane in air as such, and of its TOC disappearance, respectively, at the various initial concentrations specified for this substrate, and at $0.30 \mathrm{~W} \cdot \mathrm{cm}^{-1}$ of absorbed power per unit length of membrane.

From the observation of the values of kinetic parameters reported in Table 1, some interesting considerations may be immediately drawn.

(i) First of all, the four parameters above, obtained from data of the present paper, relatively to photodegradation and photomineralization of methane in the gas phase, substantially coincide, within the limits of experimental uncertainty, with those measured during experiments carried out in aqueous solution, both kind of experiments being performed in conditions of turbulent flow, at every value of absorbed radiation power per unit length of membrane. Furthermore, the kinetic parameters obtained in previous work [14], at a fixed value of irradiance, are in a perfect agreement with the present ones. At least, this behavior is surely shown by $\mathrm{TiO}_{2}$ immobilized in photocatalytic membranes tested.

(ii) Given the coincidence of kinetic parameters of Table 1, remarked in point (i) above, between experiments carried out in liquid and gaseous phase, Table 1 points out that, while $k_{1}$ and $k_{2}$ appear to be a clear function of irradiance, showing a saturation behavior at absorbed powers per unit membrane length greater than about $2 \mathrm{~W} \cdot \mathrm{cm}^{-1}$,

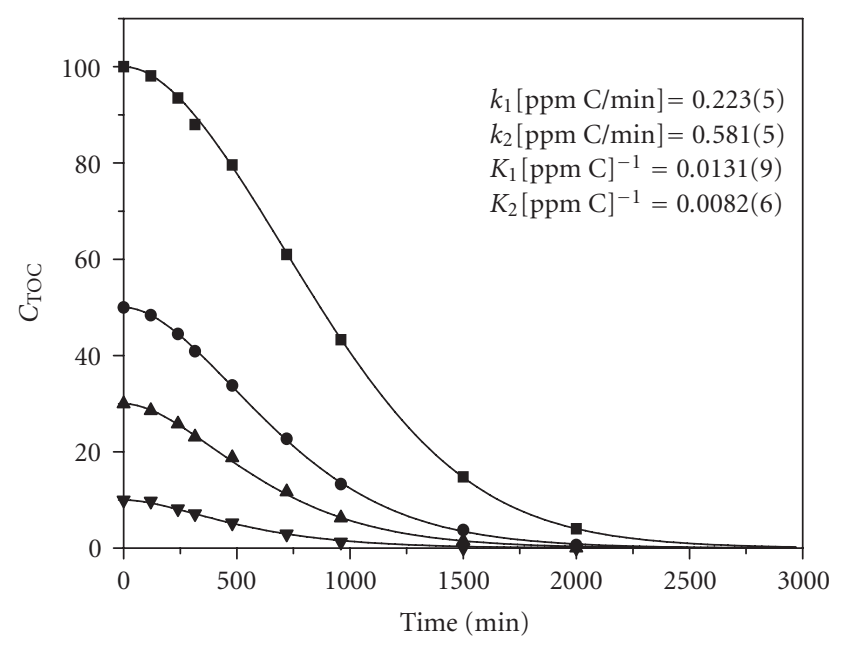

FIgURE 2: Kinetics of disappearance of total organic carbon (TOC) from gaseous methane in the laboratory-scale photoreactor (see Experimental), expressed as concentrations, $C_{\mathrm{TOC}}$ in $\mathrm{mg} / \mathrm{L}$ of carbon, which was not mineralized, as a function of time, expressed in minutes, as time necessary to treat $1 \mathrm{~L}$ of gas phase. Absorbed radiation power per unit membrane length was $0.30 \mathrm{~W} \cdot \mathrm{cm}^{-1}$ during these runs. Photocatalytic membranes used in these experiments did not contain any photopromoting agent.

$K_{1}$ and $K_{2}$ parameters show an evident independency on irradiance.

(iii) By operating in a gaseous phase saturated by water vapour, as has been done in the present paper, mineralization proceeds smoothly and completely, as it occurs in the liquid phase, and as may be observed in Figures 1 and 2. On the contrary, if relative humidity is much less than $100 \%$, and particularly when using chlorinated hydrocarbons as substrates [29], the formation of some amounts of relatively photostable intermediates, such as carbon monoxide and phosgene, has been detected. Complete mineralization was thus sensibly retarded. This inconvenience, however, may be completely obviated, other than maintaining a high humidity in the reaction medium, also by adding suitable photopromoting agents to the membrane [29]. For methane, evidently, only the first of these two experimental conditions is already able to assure complete mineralization.

(iv) Another aspect stems out from data of Table 1. In experiments of preceding work [19], carried out on gaseous methane at a fixed irradiance corresponding to $0.30 \mathrm{~W} \cdot \mathrm{cm}^{-1}$, hydrogen peroxide was aerosolized in the reactor in order to be able to compare results with those of methane solutions [14], in which hydrogen peroxide was the oxygen donor. Anyway, the two kinds of experiments gave substantially equal results. In experiments of this paper, on the contrary, the addition of hydrogen peroxide was omitted during gas-phase experiments, thus giving to dioxygen of air the role of oxygen donor in these experiments. In fact $k$ and $K$ parameters, as may be checked from results at $0.30 \mathrm{~W} \cdot \mathrm{cm}^{-1}$, are the same, in gaseous phase experiments, independently on whether hydrogen peroxide is present or not, and furthermore coincide with those of liquid phase runs. This should mean that the scavenging ability of hydrogen peroxide in 
aqueous solutions is comparable, or at least undistinguishable from that of dioxygen in air, with the photocatalytic membranes yielding substantially equal rates, in the two series of kinetic runs. On the contrary, dissolved dioxygen in water gives photomineralization rates about ten times lower than those measurable in the presence of hydrogen peroxide $[16,21]$. This marked that the difference of behavior may be reasonably attributed to the great difference between chemical potential of dioxygen in air and that of aqueous solutions, even if saturated with air, also on the light of considerations expounded in the following point $(\mathrm{v})$.

(v) By employing the same line of thoughts, as that deriving from (i) above, we may guess that, onto photocatalytic membranes, reactions at the interface control the process. In transport phenomena through the gaseous phase onto polymers, the sorption and permeation of gases and vapours in polymers have been shown to be well described over widely varying conditions by the dualmode sorption theory [30-33], in which sorption by dissolution (Henry's law) and sorption in microvoids (Langmuir isotherm) play a significant role. Factors which relate to the molecular structure of the polymer, such as polarity, hydrogen bonding, cohesive energy density, chain flexibility, steric hindrance, and cristallinity, will, among others, all have an influence on transport properties. When dealing with sorbents or reagents or catalysts immobilized onto a membrane structure, such as in the photocatalytic membranes of the present work, thermodynamics of sorption and reaction control appear to be among the most important factors in determining transport processes [34]. These reactions are ruled kinetically, and also thermodynamically, by concentration gradients, independently on diffusion and other phenomena in the bulk, either if the latter is constituted by a liquid or by a gas phase. The presence of a sorbent in a membrane structure, such as the structure which has been obtained by the photografting method used to manufacture the photocatalytic membranes employed in the present work, affords an alternative concept in membrane science and technology [22], since the endothermic step of creating a molecular-size cavity in the polymer for the reacting species, either if arriving from the gas or from the liquid phase, is virtually eliminated. At the same time, the thinnest of all conceivable membranes may be realized, consisting in a monolayer where the adsorbed molecules may interact with its surroundings. Consequently, as it has been shown [22], surface diffusion and surface reactivity must be the prevailing mechanism for transport and reaction in these membranes, since a mobile adsorption layer results, which is able to contribute efficiently to both diffusion and reactivity [22]. This surface diffusion has been inferred by the activation energy for solubility of species, either from the gas or from the liquid phase, which nearly equals the desorption enthalpy [22]. Mass transfer, in the presence of irradiation, is accompanied by the photocatalytic reactions across these photocatalytic membranes, manufactured by the photografting nanotechnology, or by similar nanotechnologies, as those used for the preparation of photocatalytic membrane structures. As a consequence, this may occur either by an activated process, most seemingly involving migration of an adsorbed unimolecular layer across the surface, or by Knudsen diffusion. The first kind of mechanism should prevail, as has been found [23, 24], when relatively strong adsorption interactions with active sites arise. This is in fact the case for photocatalytic membranes.

(vi) The similarity of behavior, and the coincidence of the $k$ and $K$ parameters (see Table 1 ), between experiments in the gas and in the liquid phase, is thus fully compatible with, and clearly interpreted by, the general mechanisms outlined in (v) above, as deduced and commented in previous studies concerning reactive membranes.

(vii) It should be also underlined that consideration on rates, based exclusively on $k$ values, following a LangmuirHinshelwood model, should not be regarded as fully and absolutely reliable. In fact, it has been shown, since long time and unequivocally $[16,21]$, that also $K$ parameters have a kinetic significance, so that these latter are integral part of a convenient and fitting model, rather than attributing to them a truly and purely physical meaning in the sense of adsorption. This notwithstanding, a rough indication based on $k$ values can be considered, at high concentrations of substrate, as complementary to the use of the rate equation, the latter being anyway the most reliable method to treat experimental data, as has been done, for example in kinetic modeling of data reported in Table 1 , in which the $k K$ factor may play the most relevant role. This behavior may be tentatively attributed to the fact that $k$ parameters rule the photochemical reactivity properly, while $K$ parameters reflect, partly at least, kinetic aspects tied to flow rates, and possibly other engineering features of the photoreactors, as it will be discussed later.

\subsection{Parameters of kinetic model as a function of flow rate in the photoreactor and of reactor geometry}

Maximum photomineralization rates, as shown by the variation of $K$ values with flow rates [16], could be attained, when operating in aqueous solutions, only if the flow rate exceeded about $3 \mathrm{~m}^{3} / \mathrm{h}$, corresponding to a Reynolds regime, in the operating conditions of the plant.

Consequently, it has been deemed useful, in the present work, to perform a similar investigation in the gas phase, by operating at a fixed value of irradiance (corresponding to $0.30 \mathrm{~W} \cdot \mathrm{cm}^{-1}$ ) and by varying the flow rate in the range $4-400 \mathrm{~m}^{3} \cdot \mathrm{h}^{-1}$. Results are shown graphically in Figure 3. It readily emerges that, while no influence on $k_{1}$ and $k_{2}$ values could be detected, outside the limits of experimental uncertainty, a variation of both $K_{1}$ and $K_{2}$ values with flow rate was operative, similar to that evidenced in liquid phase [16], so that all experimental runs for mineralization of methane in air were standardized at a flow rate of $300 \mathrm{~m}^{3} \cdot \mathrm{h}^{-1}$, in order to explore the influence of other variables, such as that of irradiance itself. This again is a clear indication of the fact that the $K$ parameters contain a kinetic contribution due to diffusion of species towards the interface of the photocatalytic membrane.

To examine further the possible influence of reactor geometry, and given that in the laboratory-scale apparatus, as well as in all the pilot plant-scale modules, the optical path was already optimized $[12,16]$, the ratio $\alpha$ between the 
overall reaction volume and the length of the membrane was varied, at the standard flow rate of $300 \mathrm{~m}^{3} \cdot \mathrm{h}^{-1}$, and at a fixed value of irradiance corresponding to $0.30 \mathrm{~W} \cdot \mathrm{cm}^{-1}$. In an annular laboratory-scale apparatus, suitable to carry out characterization or standardization procedures, such as that employed in present as well as in preceding studies, and in which batch operation is the rule, the best way to vary reactor geometry consists in varying the volume of reservoir, from and to which circulation of the reacting stream takes place. Consequently, ratio $\alpha$ above is the most suitable parameter to define reactor geometry, when reactor diameter, and optical path maximizing photochemical yields have been chosen and fixed at the most convenient values. By varying this $\alpha$ ratio from 80 to $450 \mathrm{~cm}^{3} \cdot \mathrm{cm}^{-1}$, it was confirmed that $k$ values varied accordingly, with respect to those relating to the standard value of $\alpha=160 \mathrm{~cm}^{3} \cdot \mathrm{cm}^{-1}$ used, while the $K$ values remained substantially unaffected. Consequently, $k$ values, reflecting the influence of concentrations, and expressed, for example, in $(\mathrm{mg} / \mathrm{L}) \cdot \mathrm{min}^{-1}$, were transformed into mass reacted per unit time and per unit apparent surface of membrane (e.g., by expressing them in $\mathrm{mg} \cdot \mathrm{min}^{-1} \cdot \mathrm{m}^{-2}$ ), by taking into account the variable $\alpha$ above, following the relation $\kappa=k \cdot 10 \alpha / \beta$, where $\beta$ is the circumference of the membrane, expressed in $\mathrm{cm}$. Then all these $k$ parameters gave a common $\kappa$ value, independent on reactor geometry, if expressed in the $\mathrm{mg} \cdot \mathrm{min}^{-1} \cdot \mathrm{m}^{-2}$ units above, or in any other related unit, which may be preferred. As a result, by this way, data may be standardized and compared quite easily, even in different experimental conditions.

\subsection{Modeling of quantum yields as a function of absorbed power per unit length of membrane and of substrate concentration}

By (14), in which the $K$ values substantially coincided with $K_{2}$ of Table 1 , and by applying the procedure described above (see Experimental), the $\Phi_{\infty}$ values as a function of the absorbed radiant power per unit length of photocatalytic membrane, expressed in $\mathrm{W} \cdot \mathrm{cm}^{-1}$, were obtained and reported in Figure 4, both for experiments carried out in the gas phase (red symbols) and for experiments performed in aqueous solutions (blue symbols). The practical coincidence between these two sets of values, as discussed above, readily appears. The mean values of $\Phi_{\infty}$ between these two sets of experiments are reported in Figure 5.

To explain the behavior of sigmoid curves, such as that of Figures 4 or 5, a competition kinetics of the reaction of hydroxyl radicals with themselves to give hydrogen peroxide, accompanied by the reaction of these radicals, as well as of superoxide anion radical and/or its conjugate acid, with the substrate and intermediates, leading to mineralization, may be envisaged, such as given by reaction (a) on one side and reactions (b) and $\left(b^{\prime}\right)$ on the other.

Reaction (a) corresponds to the formation of hydrogen peroxide by recombination of hydroxyl radicals, $d C_{\mathrm{H}_{2} \mathrm{O}_{2}} / \mathrm{d} t$, where $t$ is time,

$$
\cdot \mathrm{OH}+\cdot \cdot \mathrm{OH} \longrightarrow \mathrm{H}_{2} \mathrm{O}_{2}
$$

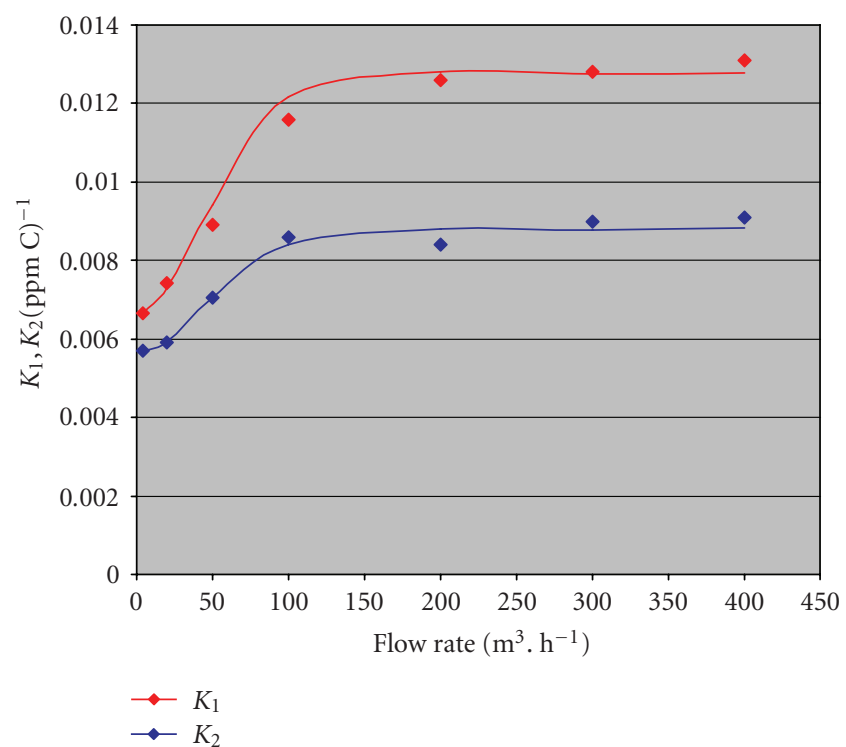

Figure 3: Variation of $K_{1}$ and $K_{2}$ parameters, expressed in $(\mathrm{ppm} \mathrm{C})^{-1}$ (see kinetic modeling in Experimental), as a function of flow rate $\left(\mathrm{m}^{3} \cdot \mathrm{h}^{-1}\right)$, for photomineralization of methane in air, and experiments carried out at a fixed irradiance corresponding to $0.30 \mathrm{~W} \cdot \mathrm{cm}^{-1}$. The mean values of $k_{1}$ and $k_{2}$ parameters, resulting from modeling of these same experiments, were sensibly constant $\left(k_{1}=0.225 \pm 0.005 \mathrm{ppm} \mathrm{C} \cdot \mathrm{min}^{-1} ; k_{2}=0.578 \pm\right.$ $\left.0.007 \mathrm{ppm} \mathrm{C} \cdot \mathrm{min}^{-1}\right)$, independently on values of flow rates. Photocatalytic membranes used in the relative experiments did not contain any photopromoting agent.

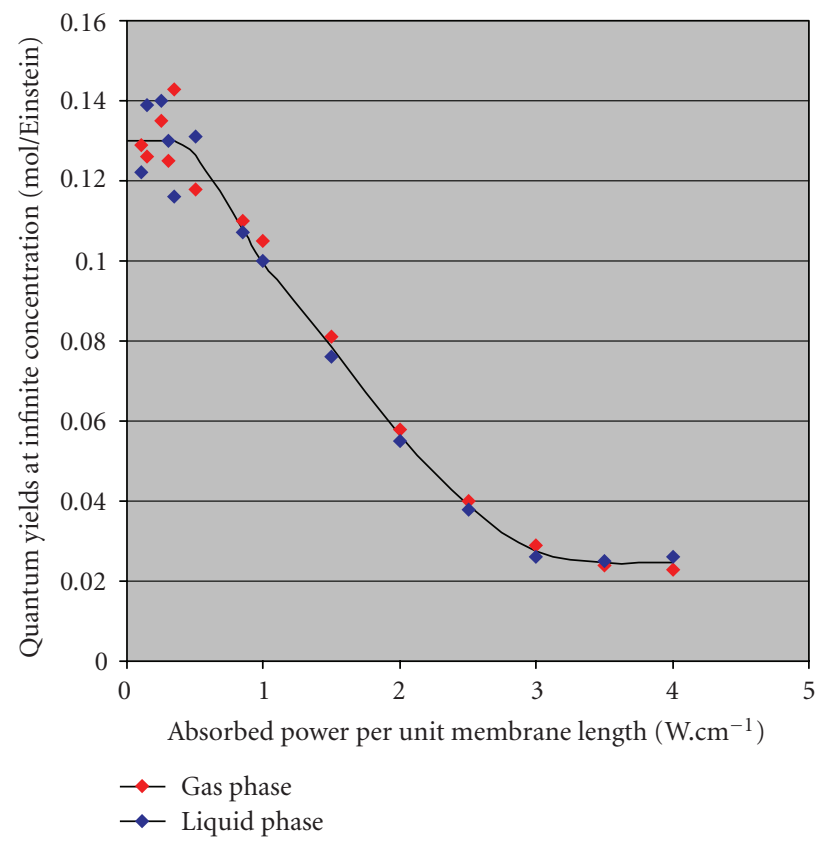

Figure 4: Quantum efficiencies $\Phi_{\infty}$ (mol/Einstein), extrapolated by (14) (see Experimental), at infinite concentration of substrate, for methane in air (red dots) and in aqueous solution (blue dots), as a function of absorbed power per unit length of irradiated photocatalytic membrane, expressed as $\mathrm{W} \cdot \mathrm{cm}^{-1}$. Photocatalytic membranes used in the relative experiments did not contain any photopromoting agent. 


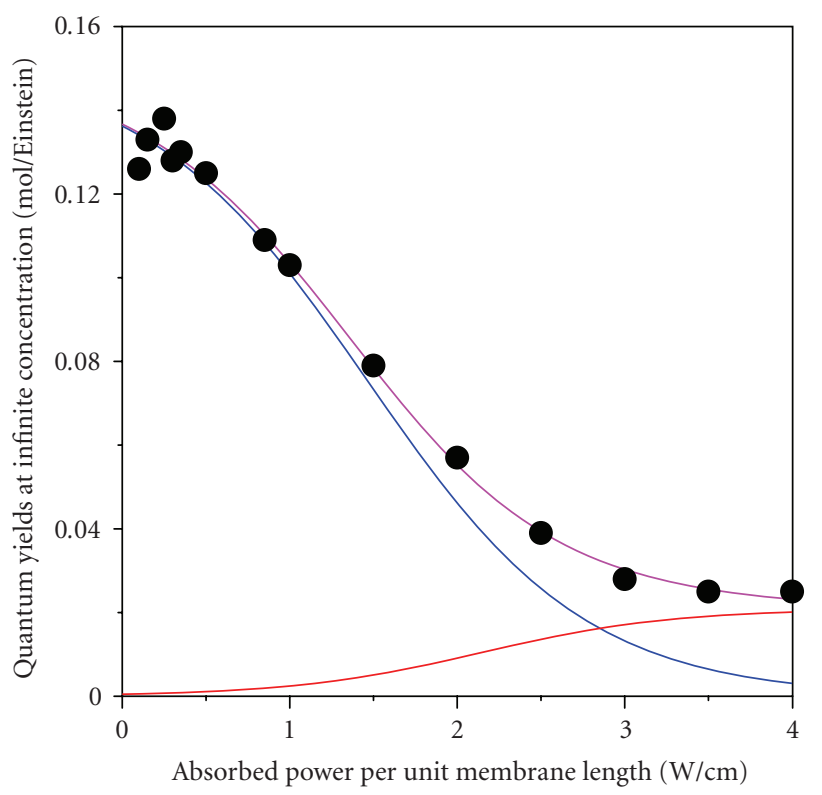

Figure 5: Quantum efficiencies $\Phi_{\infty}$ (mol/Einstein) of methane, extrapolated by (17), at infinite concentration of substrate, evaluated as mean values (black dots) relative to measurements in aqueous solution and in the gaseous phase, reported in Figure 4, as a function of absorbed power per unit length of irradiated photocatalytic membrane, expressed as $\mathrm{W} \cdot \mathrm{cm}^{-1}$. The blue curve represents the calculated contribution of reaction (b), as modeled in the present work, decreasing with increasing power. The red curve represents the calculated contribution of reaction $\left(b^{\prime}\right)$, as modeled in the present work, increasing with increasing power. The mauve curve represents equation modeled in the present work, as a sum of both these contributions. Photocatalytic membranes used in the relative experiments did not contain any photopromoting agent.

and its rate $r_{\mathrm{a}}$ may be written as

$$
r_{\mathrm{a}}=k_{\mathrm{a}} \cdot C \cdot \mathrm{OH}^{2},
$$

where $k_{\mathrm{a}}$ is the rate constant of reaction (a), and $C \cdot \cdot_{0 H}$ is the concentration of hydroxyl radicals.

Reaction (b) is given by

• $\mathrm{OH}+$ substrate (or intermediates) $\longrightarrow$ mineralization,

and its rate $r_{\mathrm{b}}$ may be written as

$$
r_{\mathrm{b}}=k_{\mathrm{b}} \cdot C_{\mathrm{S}} \cdot C \cdot \mathrm{OH}
$$

where $k_{\mathrm{b}}$ is the rate constant of reaction (b), and $C_{\mathrm{S}}$ is the concentration of substrate or intermediates, on the surface of the photocatalytic membrane on to which mineralization takes place.

Reaction $\left(b^{\prime}\right)$ by the $\mathrm{O}_{2}^{\bullet-} / \mathrm{HO}_{2}^{\bullet}$ superoxide radical couple is given by

$$
\frac{\mathrm{O}_{2}^{\bullet-}}{\mathrm{HO}_{2}^{\circ}}+\text { substrate (or intermediates) } \longrightarrow \text { mineralization, }
$$

and its rate $r_{\mathrm{b}^{\prime}}$ may be written as

$$
r_{\mathrm{b}^{\prime}}=k_{\mathrm{b}^{\prime}} \cdot C_{\mathrm{S}} \cdot C_{\mathrm{O}_{2}^{--} / \mathrm{HO}_{2}^{+}}
$$

where $k_{\mathrm{b}^{\prime}}$ is the rate constant of reaction $\left(\mathrm{b}^{\prime}\right)$.

At very low photon flows, corresponding to the upper plateau of curve of Figure 4, at which the concentration of hydroxyl radicals formed by irradiation onto the semiconductor surface is relatively low, reaction (a) is certainly negligible, with respect to reaction (b). Furthermore, in these circumstances, and particularly when operating in the presence of hydrogen peroxide as an oxygen donor, scavenging of photogenerated electrons of the conduction band $e_{\mathrm{Cb}}^{-}$should be quantitative and compatible with reactions (c) and (d) occurring at comparable rates, and followed by reaction (e) as

$$
\begin{gathered}
e_{\mathrm{Cb}}^{-}+\mathrm{H}_{2} \mathrm{O}_{2} \longrightarrow \cdot \mathrm{OH}+\mathrm{OH}^{-}, \\
e_{\mathrm{Cb}}^{-}+\mathrm{O}_{2} \longrightarrow \frac{\mathrm{O}_{2}^{\bullet-}}{\mathrm{HO}_{2}^{\bullet}} \\
\mathrm{HO}_{2}^{\bullet}+\cdot \mathrm{OH} \longrightarrow \mathrm{O}_{2}+\mathrm{H}_{2} \mathrm{O}
\end{gathered}
$$

If these conditions are working, a quantum efficiency equal or very near to the maximum one allowable may be attained. This hypothesis obviously corresponds to stating that each absorbed photon, in the optimal conditions of a membrane photoreactor, should give rise to a hydroxyl radical, at every $C_{0}$ value of (14) $C_{0}$ values being the corresponding $C_{S}$ values of (16) and (17), for each initial concentration of substrate. Following this same hypothesis, reactivity of conduction-band electrons, in the presence of hydrogen peroxide as an oxygen donor, should give rise, almost quantitatively, to molecular oxygen, or, alternatively to reactions (c)-(e), to reduced species, in the semiconductor lattice or at the interface, by reaction with donors (water itself included). If these reactions take place quantitatively, also the contribution of $r_{\mathrm{b}^{\prime}}$ to the overall rate $r$ given by

$$
r=r_{\mathrm{a}}+r_{\mathrm{b}}+r_{\mathrm{b}^{\prime}}
$$

will be negligible. Radical reactivity leading to integral mineralization of substrate should be controlled by (18), with both $r_{\mathrm{a}}$ and $r_{\mathrm{b}^{\prime}}$ much lower than $r_{\mathrm{b}}$ and consequently the $r_{\mathrm{b}} / r$ factor should reach the maximum value permissible (approaching the unity). This situation is surely achieved at very low values of the photon flow, since effectively, in these conditions, in Figure 4 the maximum allowable quantum yields for methane mineralization are operative, corresponding to reactivity of hydroxyl radicals alone, as shown by the apparent upper plateau of this curve. These values are very near to $0.125 \mathrm{~mol} /$ Einstein, which corresponds to the mineralization of methane by 8 hydroxyl radicals, as required by stoichiometry. Typically, as stated above (see Experimental), at $0.30 \mathrm{~W} / \mathrm{cm}$ (a representative value in the range of $0-0.5$ $\mathrm{W} / \mathrm{cm}$, where maximum quantum yields of Figure 4 are operative, and consequently the $r_{\mathrm{b}} / r$ ratio is unitary) this photon flow amounted to $4.45 \times 10^{-5}$ Einstein $\mathrm{s}^{-1}$. This means that, for each $\mathrm{cm}$ of membrane length, and consequently for each $\mathrm{cm}$ of length of the photoreactor, photogeneration of 
$4.45 \times 10^{-5}$ moles (of hydroxyl radicals) $\mathrm{s}^{-1} \mathrm{~cm}^{-1}$ took place. To transform this value in amount of hydroxyl radicals generated per unit time and per unit reactor volume, one should consider that in the laboratory scale module, given its overall volume in standard conditions, and owing to engineering design, the volume corresponding to each $\mathrm{cm}$ of membrane length was $160 \pm 6 \mathrm{~cm}^{3} / \mathrm{cm}$ (see Experimental). As a consequence, the production rate of $\cdot \mathrm{OH}$ radicals, always at the given absorbed power per unit length of $0.30 \mathrm{~W} / \mathrm{cm}$, was calculated as $1.11 \times 10^{-3} \mathrm{~mol} \mathrm{~s}^{-1} \mathrm{~L}^{-1}$. This linear relationship allows to evaluate the production rate of hydroxyl radicals in the upper apparent plateau of curves such as that of Figure 4, at each value of $\mathrm{W} / \mathrm{cm}$.

This mechanism, however could not rule also at high photon flows, when the quantum yields of Figure 5 from the upper apparent plateau begin to decrease with increasing photon flow, and finally reach an apparent lower second plateau. This may be due, on one side, the fact that the production rate of hydroxyl radicals, at $\mathrm{W} / \mathrm{cm}$ values higher than about 0.5 , should vary with photon flow by a nonlinear relationship, and their evaluation is possible, by supposing that $C \cdot \mathrm{OH}$ decreases exponentially with increasing $\mathrm{W} / \mathrm{cm}$ values

$$
C \cdot \mathrm{OH}=f \cdot e^{-g(\mathrm{~W} / \mathrm{cm})},
$$

with $f$ and $g$ positive constants.

On the other side, with increasing photon flow, and with decreasing rate of hydroxyl radicals production, the rate of the generation of superoxide radical couples, $\mathrm{O}_{2}^{\bullet-} / \mathrm{HO}_{2}^{\bullet}$, increases. The $\mathrm{C}_{\mathrm{O}_{2}^{-}} / \mathrm{HO}_{2}^{-}$, as a function of absorbed power per unit length of membrane, may be assumed to vary according an equation of the same kind as (19), but with a negative $g$ constant, as the production of these radicals should increase with increasing irradiance, in a complementary way by which hydroxyl radicals decrease.

Reaction $\left(b^{\prime}\right)$ thus yields a supplementary contribution to mineralization, besides that due to the photocatalytic reactivity of holes onto the semiconductor surface. In other words, to the $r_{\mathrm{b}}$ contribution to mineralization, a further contribution $r_{\mathrm{b}^{\prime}}$ should be added, deriving from the concentration of superoxide radical anion and/or its conjugate acid generated by reaction $(\mathrm{d})$. The overall contribution to mineralization, $\left(r_{\mathrm{b}}+r_{\mathrm{b}^{\prime}}\right) / r$, can be approximated by a weighted sum of the two contributions (b) and $\left(\mathrm{b}^{\prime}\right)$ as

$$
\begin{aligned}
& \frac{r_{\mathrm{b}}+r_{\mathrm{b}^{\prime}}}{r} \\
& \cong y_{(\mathrm{calc})}=\frac{f_{1}}{\left[1+e^{\left.-g_{1}\left(\mathrm{~W}-W_{1}\right) / \mathrm{cm}\right]}+\frac{f_{2}}{\left[1+e^{-g_{2}\left(\mathrm{~W}-W_{2}\right) / \mathrm{cm}}\right]} .\right.} .
\end{aligned}
$$

The error sum, $G\left(f_{1}, g_{1}, W_{1}, f_{2}, g_{2}, W_{2}\right)=\sum_{i=1}^{n} w_{i}\left[y_{(\exp )}^{i}-\right.$ $\left.y_{(\text {calc })}^{i}\right]^{2}$, is minimized with respect to $f_{1}, g_{1}, W_{1}, f_{2}, g_{2}$, and $W_{2}$ parameters, to find the best model (20) that fits the data. As shown in Figure 5 for methane, the calculated curve (red curve) perfectly fits experimental data, and gives rise to a sigmoid curve, with two apparent plateaux values, as found experimentally.

In Figure 5, the contributions to quantum yields given by these two processes have been plotted as a function of $\mathrm{W} / \mathrm{cm}$.

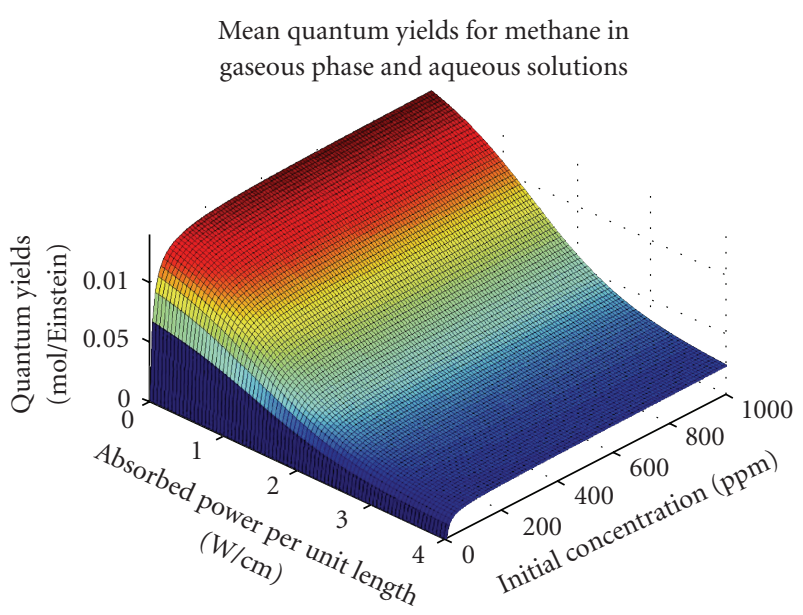

FIGURE 6: Quantum yields $\Phi_{0}$ (mol of methane/Einstein) for photomineralization of methane, as a function of initial concentration $C_{0}$, expressed as $\mathrm{mg} / \mathrm{L}$ of carbon, and of absorbed power per unit length of lamp (and membrane), expressed as $\mathrm{W} \cdot \mathrm{cm}^{-1}$. Quantum yields are expressed as means of values, from experiments in gaseous phase and in aqueous solutions. Photocatalytic membranes used in these experiments did not contain any photopromoting agent.

It clearly appears that the contribution (blue curve) of hydroxyl radicals to mineralization decreases with irradiance, while the contribution (mauve curve) of superoxide anion radical and its conjugate acid increases.

Finally, if the best curve

$y_{(\text {calc })}=\frac{0.15088}{\left[1+e^{1.5246(\mathrm{w}-1.4629) / \mathrm{cm}]}\right.}+\frac{0.020853}{\left[1+e^{-1.7655(\mathrm{w}-2.1448) / \mathrm{cm}]}\right.}$,

calculated for methane, is coupled with (14), a threedimensional graph results (see Figure 6), in which quantum yields $\Phi_{0}$ may be plotted and rationalized as a function of initial concentration, $C_{0}$, and of irradiance, in the form of the absorbed power per unit length of photocatalytic membrane, $\mathrm{W} / \mathrm{cm}$, which has been defined and used in the present paper.

To sum up, only the model given by both reactions (b) and $\left(b^{\prime}\right)$, in competition with $(a)$, is completely compatible with experimental data, and able to represent, fully satisfactorily, the dependence of quantum yields on irradiance values.

\subsection{Modeling of quantum yields, at high irradiance values, as a function of photopromoter concentration}

For the experiments carried out by photocatalytic membranes coimmobilizing the photopromoter together with titanium dioxide, the sigmoid shape of curves such as that of Figure 5 changed with increasing concentration of photopromoter, and the curves were flattened, as reported in the example of Figure 7, at a concentration of photopromoter corresponding to $3.0 \mathrm{~mol} / \mathrm{mol} \%$ of photopromoter vanadium with respect to titanium. This effect may be correlated to the kinetic influence of the photopromoter, reflected in the 


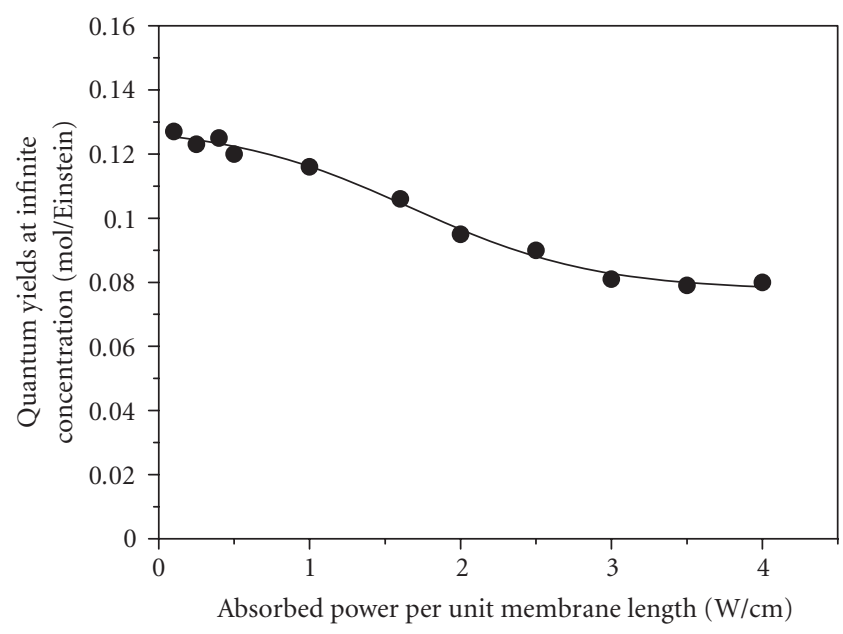

FIGURE 7: Quantum efficiencies $\Phi_{\infty}$ (mol/Einstein) of methane, extrapolated by (17), at infinite concentration of substrate, relative to measurements carried out in the gaseous phase, as a function of absorbed power per unit length of irradiated photocatalytic membrane, expressed as $\mathrm{W} \cdot \mathrm{cm}^{-1}$. Photocatalytic membranes used in the relative experiments contained the photopromoter (see Experimental) at a concentration corresponding to $3.0 \mathrm{~mol} / \mathrm{mol} \%$ of vanadium with respect to titanium present as main photocatalyst.

relationship between quantum yields and kinetic parameters. When the $\Phi_{\infty}$ values corresponding to the highest irradiances, typically at $4 \mathrm{~W} \cdot \mathrm{cm}^{-1}$, were plotted as a function of \% molar concentration of photopromoter, Figure 8 was obtained. This behavior shows that at low values of the $\% \mathrm{~mol} / \mathrm{mol}$ concentration of photopromoter vanadium, up to about 0.5 , the same $\Phi_{\infty}$ values measured in the absence of any photopromoting agent (see Figure 5) were obtained. When increasing photopromoter concentration, on the contrary, above this threshold value, $\Phi_{\infty}$ values increase considerably and approach the maximum allowable for methane $(0.125 \mathrm{~mol} /$ Einstein $)$, starting from about $5 \%$ on of photopromoter vanadium. This should mean that the decrease of quantum yield brought about by the increase of irradiance, and interpreted (see preceding paragraph) by a recombination mechanism of hydroxyl radicals may be fully compensated by the addition of appropriate photopromoters at suitable concentration. By this way, operation at high irradiance values is possible, without loosing any efficiency for the mineralization process.

\section{STANDARDIZATION OF IMMOBILIZED PHOTOCATALYTIC MATERIALS}

As recalled in Introduction, comparison of photocatalytic properties of immobilized materials, between different laboratories, is very difficult, if not impossible, owing to the variety of procedures employed in the literature. By examining kinetic curves, such as those of Figures 1 and 2, it becomes readily apparent that if criteria based on rates, either maximum or medium, are adopted, these will depend on concentration, besides the influence of reactor geometry, such as overall volume, or ratio between volume and geometri-

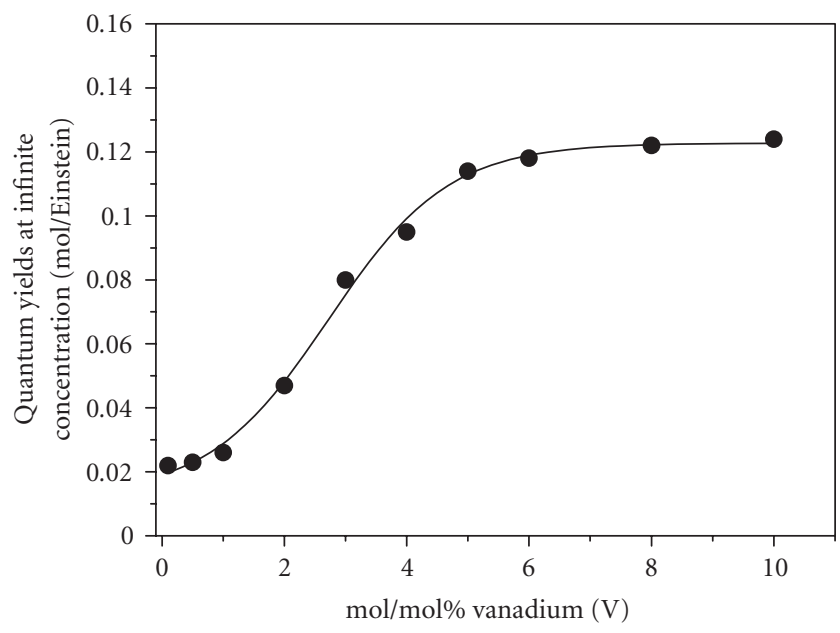

Figure 8: Quantum efficiencies $\Phi_{\infty}$ (mol/Einstein) of methane, extrapolated by (17), at infinite concentration of substrate, relative to measurements carried out in the gaseous phase, and corresponding to an absorbed power per unit length of irradiated photocatalytic membrane, expressed of $4.0 \mathrm{~W} \cdot \mathrm{cm}^{-1}$, as a function of $\mathrm{mol} / \mathrm{mol} \%$ of vanadium, used as photopromoter in the photocatalytic membranes, with respect to titanium present as main photocatalyst.

cal surface of immobilized material. The same applies also to criteria based on isotransformation times, owing to the influence of concentration on reaction order, and obviously also on criteria based on first-order kinetic constants. Their possible meaning as internal matching tools apart, these criteria, consequently, should be judged as inadequate to compare results obtained in different conditions and/or by different experimental devices, as has been thoroughly discussed in this work. In the present paper too, the influence of photochemical parameters, such as irradiance, and of engineering parameters, such as flow rate, has been clearly evidenced.

In order to reach order and rationalization, first of all a reliable kinetic model should be employed to modeling of data, such as that based on four-kinetic parameters, which has been used in the present as well as in previous work, able to fit the whole mineralization kinetic profile. This model, together with the knowledge of the influence of all variables outlined, allows to operate in quite reproducible conditions, both from the point of view of photochemistry (irradiance, possibility of isolating truly photocatalytic effects from photolysis of substrate or from photolysis of oxygen donors, influence of substrate concentration on quantum yields) and from the point of view of more strictly geometrical or engineering factors (possibility of transforming $k$ into $\kappa$ values, these latter taking into account geometrical aspects of the photoreactor used for standardization or characterization procedures, as well of the immobilized material, such as its geometrical surface). Secondly, rationalization of quantum yields, as a function of substrate concentration and irradiance allows not only to shed light onto the general photocatalytic mechanisms, at least from the perspective of modeling, but also to achieve a fully consistent and trustworthy design of industrial photoreactors. 


\section{CONCLUSIONS}

A kinetic model was employed to study photocatalytic mineralization of methane, both in air and in aqueous solutions, by an annular laboratory-scale membrane reactor, fitted with photocatalytic membranes immobilizing titanium dioxide. By a set of differential equations, four final optimized parameters, $k_{1}$ and $K_{1}, k_{2}$ and $K_{2}$, were calculated, able to fit the whole kinetic profile satisfactorily. The influence of irradiance on $k_{1}$ and $k_{2}$, as well as of flow rate on $K_{1}$ and $K_{2}$, could be rationalized by this model. The influence of reactor geometry on $k$ values could also considered, in view of standardization procedures of photocatalytic experiments, or of characterization of immobilized photocatalytic materials.

The similarity of behavior, and the coincidence of the $k$ and $K$ parameters, between experiments in the gas and in the liquid phase, is fully compatible with, and clearly interpreted by, reactions control at the interface. These reactions are ruled kinetically, and also thermodynamically, by concentration gradients, independently on diffusion and other phenomena in the bulk, either if the latter is constituted by a liquid or by a gas phase, provided conditions of turbulent flow are assured. The presence of a sorbent in a membrane structure, such as the structure which has been obtained by the photografting method used to manufacture the photocatalytic membranes employed in the present work, affords an alternative concept in membrane science and technology, since the endothermic step of creating a molecular-size cavity in the polymer for the reacting species, either if arriving from the gas or from the liquid phase, is virtually eliminated. At the same time, the thinnest of all conceivable membranes may be realized, consisting in a monolayer where the adsorbed molecules may interact with its surroundings.

Quantum yields of mineralization of substrates in annular photoreactors immobilizing the photocatalyst in a membrane structure show a Langmuirian-type dependency on initial concentration of substrates themselves, by which limiting quantum yields, corresponding to infinite concentration may be calculated, together with an apparent thermodynamic constant, coinciding with the lowest between $K_{1}$ and $K_{2}$ values, very often being $K_{1} \sim K_{2}$.

These limiting quantum yields depend on radiant power absorbed per unit membrane length, in the cylindrical geometry of photoreactors. In the low radiant power range, they take the shape of a plateau corresponding to the maximum allowable quantum yields, evaluated on the basis of a single hydroxyl radical produced per each absorbed photon, thus showing the excellent performance of the photocatalytic membrane reactors. On the contrary, at high radiant power values, another apparent plateau is evident, at a value of about $1 / 5$ (for the experimental case of methane) with respect to the maximum value. This was interpreted on the basis of the competition kinetics of hydroxyl radicals with themselves, leading to hydrogen peroxide formation, other than with substrate or intermediates molecules leading to mineralization. In this model, the contribution of hydroxyl radicals to mineralization decreases with irradiance, while the contribution of superoxide anion radical and its conju- gate acid increases. Two radical reactions thus appear to be responsible for mineralization, that of $\bullet \mathrm{OH}$ radicals, and that of the $\mathrm{O}_{2}^{\bullet-} / \mathrm{H}_{2} \mathrm{O}_{2}^{\bullet}$ radical couple, the last of which acquiring importance only in the experimental conditions of high radiating power. If these contributions are considered together, in a weighted form, the calculated equation perfectly fits experimental data, and gives rise to a sigmoid curve, with two apparent plateaux values, as found experimentally.

Finally, the action of a photopromoting agent may be easily quantified and rationalized by measuring quantum yields at infinite concentration, at high irradiance values, as a function of concentration of photopromoting agent coimmobilized in the photocatalytic membrane. When increasing photopromoter concentration above an apparent threshold value, for which no effect could be observed, $\Phi_{\infty}$ values increase considerably and approach the maximum allowable for the investigated molecule. This should mean that the decrease of quantum yield brought about by the increase of irradiance, and interpreted by a recombination mechanism of hydroxyl radicals, may be fully compensated by the addition of appropriate photopromoters at suitable concentration. By this way, operation at high irradiance values is possible, without losing any efficiency for the mineralization process.

\section{ACKNOWLEDGMENTS}

The present paper is the 81 st in a series of papers authored by Ignazio Renato Bellobono and his collaborators over the past 21 years which are collectively referred to as the Photosynthetic Membranes series. Some of us (R. Stanescu, C. Costache, and L. Bobirica) gratefully acknowledge B.I.T. srl (Milan, Italy), in the work of a permanent agreement with the Polytechnic University of Bucharest, concerning research on B.I.T. patented membranes and processes. Financial contribution by Fondazione Cariplo is also gratefully acknowledged.

\section{REFERENCES}

[1] A. L. Linsebigler, G. Lu, and J. T. Yates Jr., "Photocatalysis on $\mathrm{TiO}_{2}$ surfaces: principles, mechanisms, and selected results," Chemical Reviews, vol. 95, no. 3, pp. 735-758, 1995.

[2] M. R. Hoffmann, S. T. Martin, W. Choi, and D. W. Bahnemann, "Environmental applications of semiconductor photocatalysis," Chemical Reviews, vol. 95, no. 1, pp. 69-96, 1995.

[3] O. Legrini, E. Oliveros, and A. M. Braun, "Photochemical processes for water treatment," Chemical Reviews, vol. 93, no. 2, pp. 671-698, 1993.

[4] J. Cunningham, G. Al-Sayyed, and S. Srijaranai, "Adsorption of micropollutants onto $\mathrm{TiO}_{2}$ particles in relation to photoremediation of contaminated water, chapter 22," in Aquatic and Surface Photochemistry, G. R. Zepp and D. G. Crosby, Eds., pp. 317-348, CRC Press, Boca Raton, Fla, USA, 1994.

[5] R. W. Matthews, "Photooxidation of organic impurities in water using thin films of titanium dioxide," Journal of Physical Chemistry, vol. 91, no. 12, pp. 3328-3333, 1987.

[6] A. Mills, R. H. Davies, and D. Worsley, "Water purification by semiconductor photocatalysis," Chemical Society Reviews, vol. 22, no. 6, pp. 417-425, 1993. 
[7] M. R. Prairie, L. R. Evans, B. M. Stange, and S. L. Martinez, "An investigation of $\mathrm{TiO}_{2}$ photocatalysis for the treatment of water contaminated with metals and organic chemicals," Environmental Science \& Technology, vol. 27, no. 9, pp. 1776-1782, 1993.

[8] M. Schiavello, Photocatalysis and Environment: Trends and Applications, vol. 238 of NATO ASI Series C, Kluwer, London, UK, 1987.

[9] D. Bahnemann, "Photocatalytic detoxification of polluted waters," in The Handbook of Environmental Chemistry, P. Boule, Ed., vol. 2, part 1, pp. 185-212, Springer, Berlin, Germany, 1999.

[10] I. R. Bellobono, B. Barni, and F. Gianturco, "Pre-industrial experience in advanced oxidation and integral photodegradation of organics in potable waters and waste waters by PHOTOPERM $^{\mathrm{TM}}$ membranes immobilizing titanium dioxide and promoting photocatalysts," Journal of Membrane Science, vol. 102, pp. 139-147, 1995.

[11] M. F. J. Dijkstra, E. C. B. Koerts, A. A. C. M. Beenackers, and J. A. Wesselingh, "Performance of immobilized photocatalytic reactors in continuous mode," AIChE Journal, vol. 49, no. 3, pp. 734-744, 2003.

[12] F. Ascari, I. R. Bellobono, and P. M. Tozzi, "Kinetic modelling of pilot plant photomineralization of aqueous cibacron CR as model molecule of industrial azo dyes on titanium dioxideimmobilizing membranes," Fresenius Environmental Bulletin, vol. 12, no. 10, pp. 1195-1201, 2003.

[13] I. R. Bellobono, F. Ascari, C. Lagrasta, et al., "Kinetic modelling of photomineralization of phenol, as model molecule of aromatic micropollutants, and validation of a photochemical reactor based on photocatalytic membranes immobilizing titanium dioxide and promoting photocatalysts," Fresenius Environmental Bulletin, vol. 12, no. 12, pp. 1536-1544, 2003.

[14] I. R. Bellobono, F. Morazzoni, R. Bianchi, et al., "Laboratoryscale photomineralisation of $\mathrm{n}$-alkanes in aqueous solution, by photocatalytic membranes immobilising titanium dioxide," International Journal of Photoenergy, vol. 7, no. 2, pp. 79-85, 2005.

[15] A. V. Emeline, V. K. Ryabchuk, and N. Serpone, "Dogmas and misconceptions in heterogeneous photocatalysis. Some enlightened reflections," Journal of Physical Chemistry B, vol. 109, no. 39, pp. 18515-18521, 2005.

[16] B. Barni, A. Cavicchioli, E. Riva, et al., "Pilot-plant-scale photodegradation of phenol in aqueous solution by photocatalytic membranes immobilizing titanium dioxide (PHOTOPERM $\mathbb{R}$ process)," Chemosphere, vol. 30, no. 10, pp. 1861-1874, 1995.

[17] F. Gianturco, C. M. Chiodaroli, I. R. Bellobono, M. L. Raimondi, A. Moroni, and B. Gawlik, "Pilot-plant photomineralization of atrazine in aqueous solution, by photocatalytic membranes immobilizing titanium dioxide and promoting photocatalysts," Fresenius Environment Bulletin, vol. 6, pp. 461-468, 1995.

[18] I. R. Bellobono, G. de Martini, P. M. Tozzi, et al., "Modelling of quantum yields in photocatalytic membrane reactors immobilising titanium dioxide," International Journal of Photoenergy, vol. 2006, Article ID 26870, 8 pages, 2006.

[19] I. R. Bellobono, R. Stanescu, C. Costache, et al., "Laboratoryscale photomineralisation of $\mathrm{n}$-alkanes in gaseous phase, by photocatalytic membranes immobilising titanium dioxide," International Journal of Photoenergy, vol. 2006, Article ID 73167, 8 pages, 2006.

[20] I. R. Bellobono, R. Tacchi, E. Selli, and F. Muffato, "Photosynthetic membranes for pure and ultra pure water production," in Membrane Separation Processes, A. Green, Ed., pp. 187-193, BHRA, Cranfield, UK, 1989.

[21] B. Barni, A. Cavicchioli, E. Riva, et al., "Laboratory-scale photodegradation of phenol in aqueous solution by photocatalytic membranes immobilizing titanium dioxide," Chemosphere, vol. 30, no. 10, pp. 1847-1860, 1995.

[22] I. R. Bellobono, F. Muffato, C. Ermondi, E. Selli, and L. Righetto, "Gas separation membranes containing carbon immobilized by photochemical grafting onto polymers," Journal of Membrane Science, vol. 55, no. 3, pp. 273-281, 1991.

[23] I. R. Bellobono, F. Muffato, C. Ermondi, E. Selli, L. Righetto, and M. Zeni, "Thermodynamic study of sorption of n-alkanes onto 5A zeolites immobilized in photosynthetic membranes," Journal of Membrane Science, vol. 55, no. 3, pp. 263-272, 1991.

[24] I. R. Bellobono, E. Selli, L. Righetto, F. Muffato, and C. Ermondi, "Thermodynamic study of sorption of linear aliphatic momhydric alcohols and moncarboxylic acids from n-heptane and n-decane solution onto $\alpha$-iron(III) oxide immobilized in photosynthetic membranes," Materials Chemistry and Physics, vol. 21, no. 2, pp. 155-167, 1989.

[25] I. R. Bellobono, A. Carrara, B. Barni, and A. Gazzotti, "Laboratory- and pilot-plant-scale photodegradation of chloroaliphatics in aqueous solution by photocatalytic membranes immobilizing titanium dioxide," Journal of Photochemistry and Photobiology A, vol. 84, no. 1, pp. 83-90, 1994.

[26] F. Rota, M. Cavassi, D. Niego, et al., "Mathematical modelling of photomineralization of phenols in aqueous solution, by photocatalytic membranes immobilizing titanium dioxide," Chemosphere, vol. 33, no. 11, pp. 2159-2173, 1996.

[27] N. Serpone, E. Pelizzetti, and K. Hidaka, "Identifying primary events and the nature of intermediates formed during the photocatalyzed oxidation of organics mediated by irradiated semiconductors," in Photocatalytic Purification and Treatment of Water and Air, D.F. Ollis and H. Al-Ekabi H, Eds., pp. 225250, Elsevier, Amsterdam, The Netherlands, 1993.

[28] C. S. Turchi and D. F. Ollis, "Mixed reactant photocatalysis: intermediates and mutual rate inhibition," Journal of Catalysis, vol. 119, no. 2, pp. 483-496, 1989.

[29] I. R. Bellobono, "Advanced oxidation and integral degradation of trichloroethene in air by photocatalytic membranes immobilizing titanium dioxide and promoting photocatalysts," Life Chemistry Reports, vol. 13, pp. 63-70, 1995.

[30] W. R. Vieth, J. M. Howell, and J. H. Hsieh, "Dual sorption theory," Journal of Membrane Science, vol. 1, pp. 177-220, 1976.

[31] R. T. Chern, W. J. Koros, H. B. Hopfenberg, and V. T. Stannett, "Material selection for membrane-based gas separations," Polymeric Materials Science and Engineering, vol. 50, pp. 88-92, 1984.

[32] W. J. Koros, "Simplified analysis of gas/polymer selective solubility behaviour," Journal of Polymer Science, vol. 23, no. 8, pp. 1611-1628, 1985.

[33] A. S. Sangani, "An application of an homogenization method to a model of diffusion in glassy polymers," Journal of Polymer Science B, vol. 24, no. 3, pp. 563-575, 1986.

[34] I. R. Bellobono, F. Muffato, E. Selli, L. Righetto, and R. Tacchi, "Transport of oxygen facilitated by peroxo-bis $\left[N, N^{\prime}\right.$-ethylene bis-(salicylideneiminato)-dimethylformamide-cobalt(III)] embedded in liquid membranes immobilized by photografting onto cellulose," Gas Separation \& Purification, vol. 1, no. 2, pp. 103-106, 1987. 


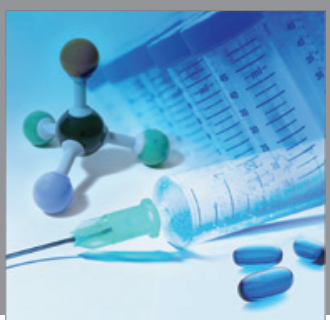

International Journal of

Medicinal Chemistry

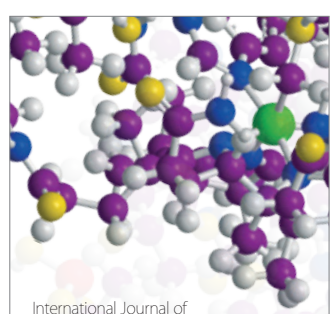

Carbohydrate Chemistry

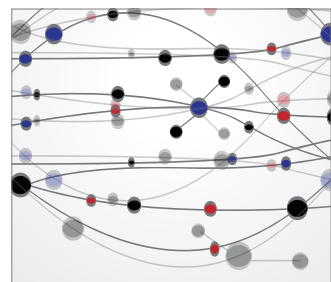

The Scientific World Journal
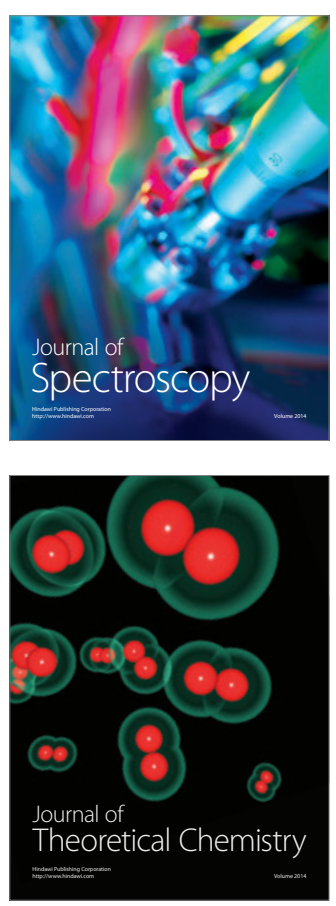
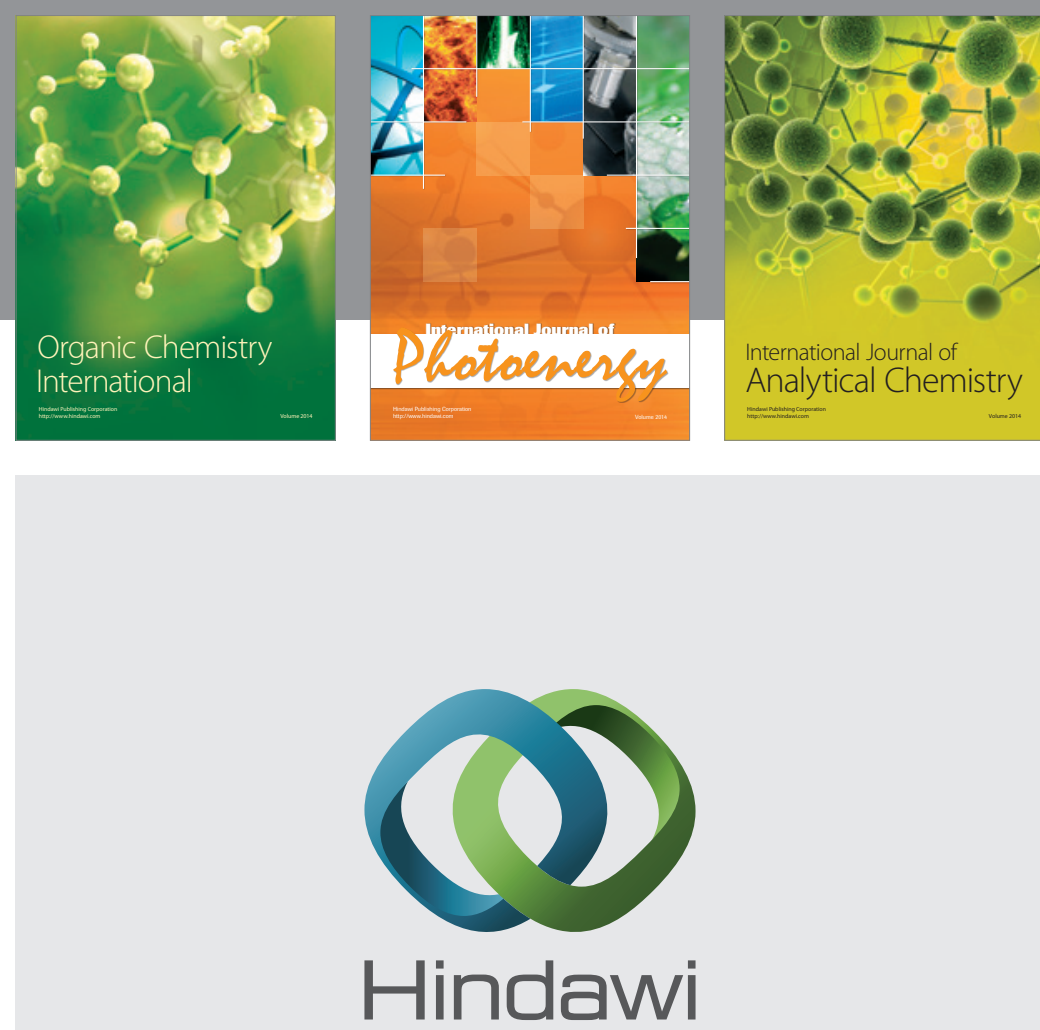

Submit your manuscripts at

http://www.hindawi.com
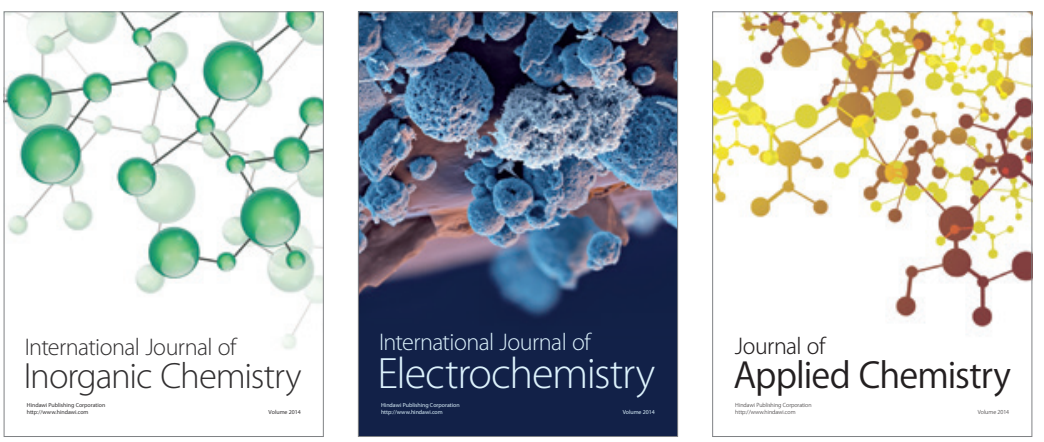

Journal of

Applied Chemistry
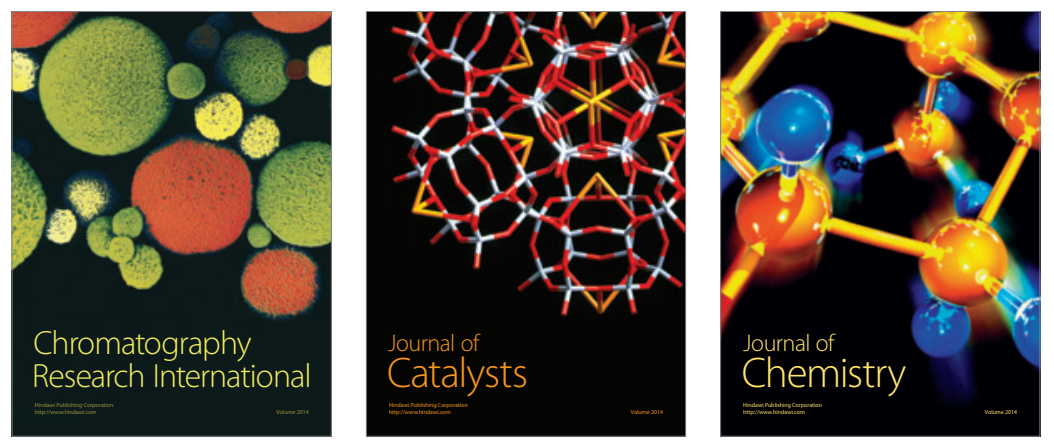
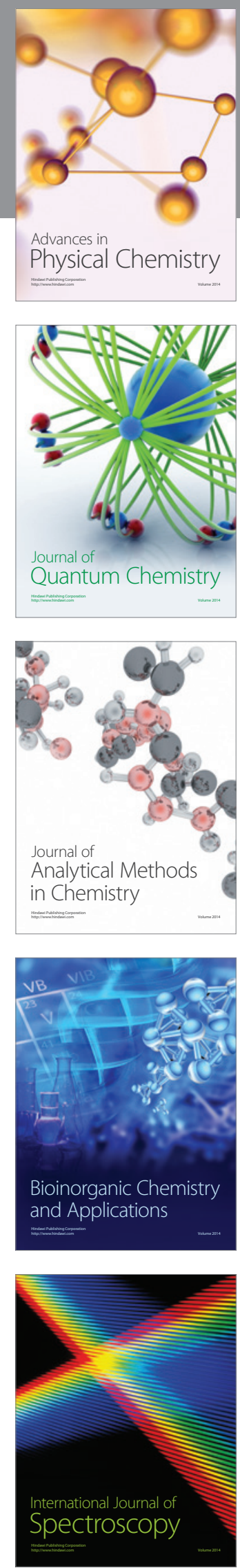